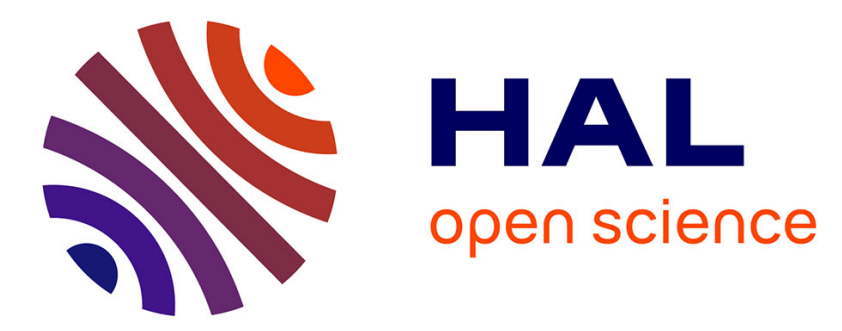

\title{
Animal spirits, fundamental factors and business cycle fluctuations
}

\author{
Stephane Dees, Srecko Zimic
}

\section{To cite this version:}

Stephane Dees, Srecko Zimic. Animal spirits, fundamental factors and business cycle fluctuations. Journal of Macroeconomics, 2019, 61, pp.103-123. 10.1016/j.jmacro.2019.103123 . hal-03285242

\section{HAL Id: hal-03285242 \\ https://hal.science/hal-03285242}

Submitted on 22 Oct 2021

HAL is a multi-disciplinary open access archive for the deposit and dissemination of scientific research documents, whether they are published or not. The documents may come from teaching and research institutions in France or abroad, or from public or private research centers.
L'archive ouverte pluridisciplinaire HAL, est destinée au dépôt et à la diffusion de documents scientifiques de niveau recherche, publiés ou non, émanant des établissements d'enseignement et de recherche français ou étrangers, des laboratoires publics ou privés.

\section{다)(1) $(5$}

Distributed under a Creative Commons Attribution - NonCommerciall 4.0 International 


\title{
Animal Spirits, Fundamental Factors and Business Cycle Fluctuations*
}

\author{
Stephane Dées ${ }^{\dagger} \quad$ Srečko Zimic ${ }^{\ddagger}$
}

May 2, 2019

\begin{abstract}
We explore empirically the role of noisy information in cyclical developments to separate fluctuations due to genuine changes in fundamentals from those driven by temporary animal spirits (or noise shocks). Exploiting the fact that the econometrician has a richer dataset in some dimensions than the consumers, we use a novel identification scheme in a structural VAR framework and show that noise shocks are important drivers of business cycle fluctuations. In particular, noise shocks play a large role in consumption expenditures showing how false perceptions about future fundamentals influence consumer behaviors.
\end{abstract}

Keywords: Technology shocks, Noise shocks, Animal spirits, Business Cycles, Identification, Structural Vector Autoregression, Kalman Filter, Signal-extraction problem

JEL Classification: C32, E32

\footnotetext{
*Any views expressed represent those of the authors and not necessarily those of the Banque de France, the European Central Bank or the Eurosystem. We are especially grateful to Fabio Canova and Evi Pappa. We would also like to thank Luca Benati, Luca Gambetti, Gianni Amisano, Marek Jarocinski, Jochen Guentner, Yi Wen and participants at the IAAE 2014 Annual Conference, ASSA 2018 Annual Meetings as well as seminar participants at the ECB for helpful comments. Any remaining errors are the sole responsibility of the authors.

${ }^{\dagger}$ Banque de France and Larefi (University of Bordeaux), Contact information: Banque de France, 31 rue Croix des Petits Champs, 75049 Paris cedex, France. Email: stephane.dees@banque-france.fr; tel: +33142929026.

¥European Central Bank, Contact information: European Central Bank, Sonnemannstrasse 22, 60314 Frankfurt am Main, Germany. Email: srecko.zimic@ecb.europa.eu; tel.: + 496913444388.
} 


\title{
Animal Spirits, Fundamental Factors and Business Cycle Fluctuations
}

\author{
May 2, 2019
}

\begin{abstract}
We explore empirically the role of noisy information in cyclical developments to separate fluctuations due to genuine changes in fundamentals from those driven by temporary animal spirits (or noise shocks). Exploiting the fact that the econometrician has a richer dataset in some dimensions than the consumers, we use a novel identification scheme in a structural VAR framework and show that noise shocks are important drivers of business cycle fluctuations. In particular, noise shocks play a large role in consumption expenditures showing how false perceptions about future fundamentals influence consumer behaviors.
\end{abstract}

Keywords: Technology shocks, Noise shocks, Animal spirits, Business Cycles, Identification, Structural Vector Autoregression, Kalman Filter, Signal-extraction problem

JEL Classification: C32, E32 


\section{Introduction}

The 2008/09 financial crisis and the Great Recession that followed has led many observers and academics to interpret the recession as a sharp decline in aggregate demand resulting from a collapse in confidence. The sharp collapse in confidence might have led to a selffulfilling shock to expectations. ${ }^{1}$ This suggests that the way households and firms form expectations of the future may therefore be an independent driving force of the business cycle.

The idea that agents' beliefs may be a source of economic fluctuations has a long history. Pigou (1929) was among the first to stress that expectations were key in explaining business cycles, as psychological factors (i.e. undue optimism and pessimism) lead entrepreneurs to make errors when forming their expectations about future profits. These errors generate cycles through rises and falls in investment. These psychological factors are also very often called "animal spirits", following Keynes (1936). Although the Real Business Cycle theory does not incorporate such psychological factors in its explanation of economic fluctuations, Pigou's ideas have recently been reintroduced into the theory of cycles in the context of equilibrium business cycle models, notably by Beaudry and Portier (2006) or Jaimovich and Rebelo (2009). In these models, although technology remains the only determinant of output in the long run, news about future fundamentals can imply a change in expectations, which affects agents' behaviors in the short run in anticipation of fundamental changes. However, economic agents receive only noisy signals about future technology, leading to expectational errors (Lorenzoni (2009)). If the information subsequently appears to have been wrong (i.e. it was just noise), the agents readjust their expectations and decisions accordingly. Conversely, if the information proves correct, the economy adjusts gradually to the level of activity consistent with technology. These changes in expectations generate economic fluctuations, both in the short and the long term.

Blanchard et al. (2013) explore the role of noisy information in cyclical developments empirically, separating fluctuations that are due to genuine changes in supply (news shocks) from those due to temporary expectational errors (noise shocks). They show that the identification of those shocks is only possible via the estimation of a full structural model, such as the one in Barsky and Sims (2012) or Hürtgen (2014). Since economic agents face a signal extraction problem when separating news from noise shocks, the econometrician, using the same data, cannot use structural VARs to recover such shocks.

\footnotetext{
${ }^{1}$ See e.g. European Central Bank (2013),Farmer (2012) and Bacchetta et al. (2012)
} 
However, although this point is valid in real time, the econometrician can potentially have access to a richer dataset in hindsight.

Based on this idea, this paper shows that a structural VAR model can be used to identify news and noise shocks. First, while economic agents can observe only current and past data, the econometrician can also observe "future" data. In other words, by using the data from the whole sample, the econometrician can have a better estimate of the technological trends than the economic agents. Second, the economic agents only observe real-time data, while the econometrician also has access to revised data.

Recent papers have also proposed alternative ways to solve the issue put forward by Blanchard et al. (2013). Forni et al. (2017) use a modification of the structural VAR method to disentangle real from noise shocks, using future data and future residuals. However, their methodology is applicable only when the true state of the economy can be exactly retrieved. In this paper we show that our methodology can be used to approximately identify supply and noise shocks in more general models, such as that of Blanchard et al. (2013), in which the true state of economy can never be retrieved. Masolo and Paccagnini (2018) identify noise shocks by exploiting the informational advantage of the econometricians, who have access, with the benefit of hindsight, to data revisions as well. While we also use the noisy early data releases to identify the noise shocks, we also base our identification of agents' misperceptions about the future using forecast errors regarding trend output. Other recent research include Enders et al. (2013), who identify noise shocks in a standard VAR model by including 'nowcast errors', defined as the difference between actual GDP growth (available during the next period) and growth estimated contemporaneously by professional forecasters. Similarly, Benhima and Poilly (2017) also use a sign restriction approach that relies on survey expectation errors. By expanding the identification strategy with expectation errors on inflation, they are also able to identify separately supply- and demand-noise shocks. Compared to those authors, the main innovation of our approach is to make use of potential output to measure the misperceptions of economic agents. We therefore use data at much later dates to form estimations of the output gap, which is then used for the identification of noise shocks. Using potential output has two advantages. First, it uses more data that becomes available at futures dates, instead of using only information available during the next period. Second, it is likely to be more directly linked to agents' decisions regarding consumption.

We start our analysis by designing a slightly modified version of the model by Blanchard et al. (2013) and show how a structural VAR can be used to disentangle news and noise shocks. The methodology relies on the forecast errors consumers make when 
predicting the trend of GDP. These forecast errors are estimated by exploiting the fact that the econometricians have access to 'future' and revised data. This approach is first used to show how the superior information set of the econometrician can be separated into more precise information and information that is available at a later date. We apply thereafter this method to U.S. data and identify supply and noise shocks in two separate VAR models: a simple two-variable VAR model relying on restrictions based on our theoretical model and a large-scale VAR model where the empirical restrictions on predictions are derived from the full structural model of Hürtgen (2014). Our empirical exercises show that the identified supply and noise shocks have effects as predicted by our theoretical model. A permanent supply shock has an expansionary effect, which builds through time until all variables settle at a new, higher value. A noise shock also has an expansionary effect on the economy, but the impact fades away over time until all variables settle at their initial value. Nevertheless, noise shocks are as important as permanent supply shocks for business cycle fluctuations, explaining 25 percent of output variations at business cycle frequencies. On the other hand, permanent shocks drive the economy in the long run, but also account for around 20 percent of output variations at business cycle frequencies. Interestingly, consumption is even more affected by noise shocks (25-30 percent of variations in consumers' expenditures at business cycle frequencies), showing the extent to which false perceptions about future fundamentals play a role in consumers' behaviors.

After a presentation of the theoretical model in Section 2, we explain in Section 3 the problems related to identifying noise shocks in the data with structural VAR models. We then show that, by using future observations and revisions of data, we can circumvent those problems and still use VAR models to extract supply and noise shocks. In Section 4 , we present empirical evidence on the effects of supply and noise shocks, by applying our methodology to U.S. data. Several robustness checks are performed in Section 5, all confirming our main results. We conclude in Section 6.

\section{Model}

This section presents a simple model, similar to the model proposed by Blanchard et al. (2013), in which consumers decide their level of consumption based on their expectations about the economy's long-run fundamentals. Long-run economic fundamentals are driven by productivity developments, which depend on a structural shock with permanent effects (i.e. a technology shock) that builds up gradually. Consumers do not observe the 
structural shock but only a noisy signal. This additional source of fluctuations is called a noise shock (or an "animal spirits" shock). As in Blanchard et al. (2013), consumers solve a signal extraction problem and decide their level of consumption on the basis of their expectations about future technology.

\subsection{The structure of the model}

We assume first that consumption is determined by the following Euler equation:

$$
c_{t}=E_{t}\left[c_{t+1} \mid \mathcal{I}_{t}\right]
$$

where $c_{t}$ is consumption and $E_{t}\left[c_{t+1} \mid \mathcal{I}_{t}\right]$ is expected consumption in period $t+1$ based on the information set at time $t$, denoted $\mathcal{I}_{t}$. The supply side of the economy is completely determined by the demand side, which implies that output, $y_{t}$, equals consumption:

$$
y_{t}=c_{t}
$$

Output depends on utilization, $u_{t}$ and the level of technology, $a_{t}$, in a linear fashion, $y_{t}=a_{t}+u_{t}$. Given the level of technology and consumption, utilization adjusts to produce the demanded level of output. However, in the long-run, output is equal to its natural level, and utilization is equal to zero, implying:

$$
\lim _{j \rightarrow \infty} E_{t}\left[c_{t+j}-a_{t+j}\right]=0
$$

As is shown in Blanchard et al. (2013), equation (2.3) can be derived from a standard New-Keynesian model with Calvo pricing, when the frequency of price adjustment goes to zero. Combining (2.1) and (2.3) gives:

$$
c_{t}=\lim _{j \rightarrow \infty} E_{t}\left[a_{t+j} \mid \mathcal{I}_{t}\right]
$$

which implies that consumption depends on expectations about long-run productivity.

The relevant state of the economy is productivity, $a_{t}$, which follows the process:

$$
a_{t}=(1+\rho) a_{t-1}-\rho a_{t-2}+\epsilon_{t}
$$

where $\epsilon_{t} \sim \mathcal{N}\left(0, \sigma_{\epsilon}^{2}\right)$ is a technology shock. Given that productivity is modeled as a process with a stochastic trend, the technology shock $\epsilon_{t}$ will have a permanent effect on 
productivity.

\subsection{Information structure}

The crucial difference with a standard DSGE model lies in the information structure. Consumers do not observe productivity directly, but observe only a noisy signal of productivity, $s_{t}$ :

$$
s_{t}=a_{t}+v_{t}
$$

where $v_{t} \sim \mathcal{N}\left(0, \sigma_{v}^{2}\right)$ is a noise shock. The signal extraction problem can be rewritten as a state-space model:

- State Equation

$$
\left[\begin{array}{c}
a_{t \mid t} \\
a_{t-1 \mid t}
\end{array}\right]=A\left[\begin{array}{c}
a_{t-1 \mid t-1} \\
a_{t-2 \mid t-1}
\end{array}\right]+B\left[\begin{array}{c}
\epsilon_{t} \\
v_{t}
\end{array}\right]
$$

- Observation Equation

$$
s_{t}=C\left[\begin{array}{c}
a_{t \mid t} \\
a_{t-1 \mid t}
\end{array}\right]+D\left[\begin{array}{c}
\epsilon_{t} \\
v_{t}
\end{array}\right]
$$

where $a_{t \mid t}=E_{t}\left[a_{t} \mid \mathcal{I}_{t}\right]$ and the matrices $A, B, C$ and $D$ depend on parameters. ${ }^{2}$ We assume that consumers know the underlying parameters of the economy and the distributions of shocks, in other words they know the matrices $A, B, C$ and $D$, and thus they can use a Kalman filter to form their expectations about the current state of technology. ${ }^{3}$

Figure 1 shows, for simulated data, the developments in productivity, i.e. potential output growth, displayed by the smoothed line in the upper panel. Consumers receive a noisy signal, which is by definition very volatile and form their expectations by solving the signal extraction problem. Consumers' expectations about technology are not accurate as they are affected by the noise shock. The lower panel shows the forecast errors made by consumers when predicting the state of the economy.

\footnotetext{
${ }^{2}$ We use the same calibration as used in Blanchard et al. (2013): $\rho=0.89, \sigma_{\epsilon}=0.07$ and $\sigma_{v}=0.89$

${ }^{3}$ Note that we are assuming that consumers do not observe utilization, otherwise agents could differentiate between the technology shock and the noise shock by observing utilization. Utilization is anyway difficult to observe at the macroeconomic level, even though proxies for the utilization of labor can be found (e.g. hours worked). Moreover, we could also remove this assumption by introducing a transitory technology shock, as in Blanchard et al. (2013). By ignoring this extension, we aimed at keeping the presentation of the signal-extraction problem as simple as possible.
} 
Figure 1: Simulated technology, signal and consumer's expectations (upper panel) and forecast error (lower panel)
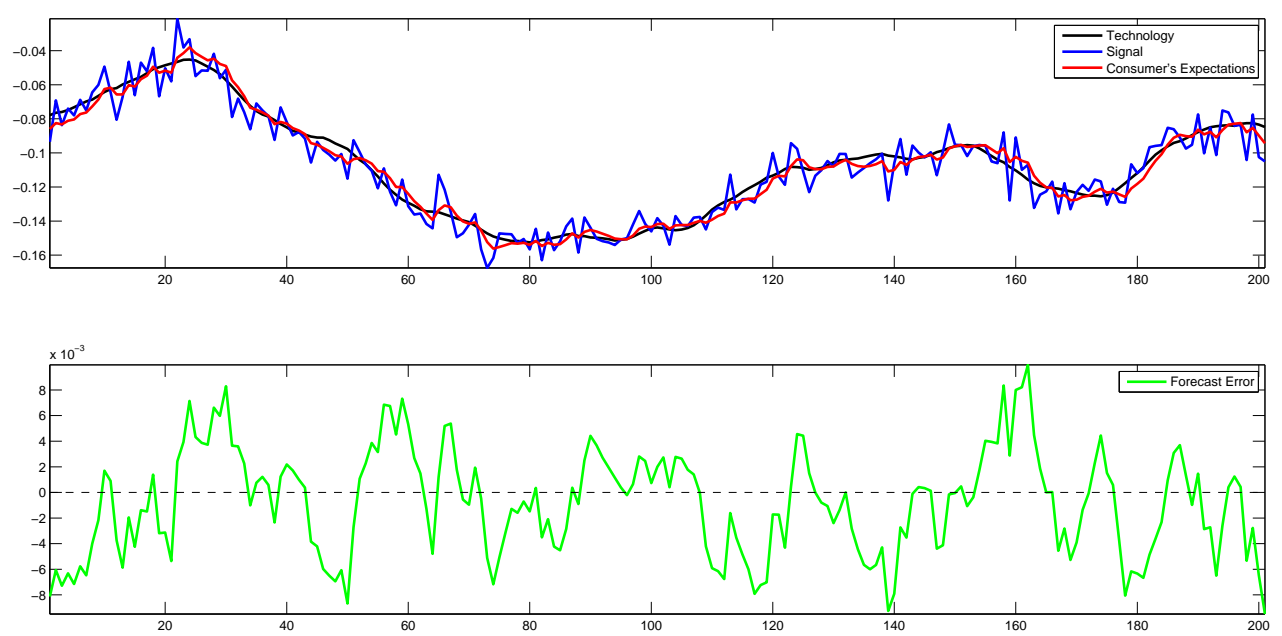

The black line represents the underlying technological process, which agents do not observe. The agents observe a signal (blue line) and via a Kalman filter, they form their expectations about technology (red line). The difference between their expectations and the true state of technology - forecast error - is represented in the graph below with the green line.

\subsection{Model solution}

Once we obtain the agent's expectations about the state of technology, by standard Kalman filtering, the solution of the model is straightforward. From Equation (2.4) and (2.5) we can derive the solution of consumption in terms of the agent's expectations about the state of technology:

$$
c_{t}=\frac{1}{1-\rho}\left(a_{t \mid t}-\rho a_{t-1 \mid t}\right)
$$

where we have used the same notation as in the setup of the Kalman filter, $a_{t \mid t}=E_{t}\left[a_{t} \mid \mathcal{I}_{t}\right]$ and $a_{t-1 \mid t}=E_{t}\left[a_{t-1} \mid \mathcal{I}_{t}\right]$. The other variables are a linear function of technology:

$$
\begin{gathered}
y_{t}=c_{t} \\
u_{t}=a_{t}-y_{t}
\end{gathered}
$$

Following a supply (or technology) shock, $\epsilon_{t}$, in the absence of noise shocks, the signal, $s_{t}$, is equal to $a_{t}$ (see Equation (2.6)). Consumers underpredict the actual technological improvement in the short term, leading to a negative forecast error. Over time, as the signal confirms the increase in productivity, the expectations converge gradually to the 
new state of the economy and the forecast error fades away. Consumption improves faster in anticipation of the long-term effects of the supply shock.

Conversely, a noise shock is characterized by a one-off change in the signal and no change in productivity. In the short term, consumers believe that the positive signal could potentially be related to a change in technology and their expectations about the state of the economy are positive. Over time, they realize that the signal was just noise and the expectations gradually adjust to the initial state. As a result, the consumers' forecast error is positive in the short term and returns gradually to zero over time. This shortterm optimism also leads consumption to be positively affected by the noise shock, as the shock has been unduly interpreted as a supply shock. Over time, when the information becomes more accurate, they realize their forecast error and readjust their consumption expenditures.

It is worth noting that, as in Lorenzoni (2009), the only source of exogenous uncertainty is the level of technology $a_{t}$ and the noise shocks have therefore features of aggregate demand shocks. As with technology shocks, the noise shocks are unobservable because they are related to a noisy signal of productivity. As a result, only these two shocks can lead in the same period to forecast errors about the current state of technology. In a more complex model, we could therefore assume that all other sources of disturbances are observable and do not lead to such forecast errors. Moreover, the general idea developed here can easily be carried over in more complex models with capital accumulation, nominal rigidities or habit persistence. For instance, Blanchard et al. (2013) show that such results are robust when they embed the same productivity process and information structure in a small-scale DSGE model, including investment and capital accumulation, nominal rigidities and a monetary policy rule. In our empirical exercise, we will use the structural model of Hürtgen (2014), whose predictions will be the basis of our VAR model restrictions.

\section{From the model to a structural VAR}

In this section, we focus on the way to identify and estimate supply and noise shocks. Since consumers only receive a noisy signal about the shocks, it is not possible to recover supply and noise shocks from actual data on $c_{t}$ and $s_{t}$. First, we show that a VAR representation of the model faces an issue of non-invertibility and non-fundamentalness. Second, as the issue is mainly related to the fact that the information set used by consumers is not accurate enough to recover the shocks, we show that having a superior 
information set can help solve the problem. Third, we show how a structural VAR approach can be used in this context.

\subsection{Singularity of VAR models}

Let us consider running a VAR with consumption, $c_{t}$, and the signal, $s_{t}$, to obtain the structural shocks. From Equation (2.9) we know that consumption is a linear function of expectations about the current and past states of the economy:

$$
c_{t}=f\left(E_{t}\left[a_{t} \mid \mathcal{I}_{t}\right]\right)
$$

As such expectations are formed by a Kalman filtering approach, which is a linear filter, we also know that these expectations are a linear function of current and past signals:

$$
E_{t}\left[a_{t} \mid \mathcal{I}_{t}\right]=g\left(s_{t}, s_{t-1}, \ldots\right)
$$

Equations (3.1) and (3.2) imply that consumption is a linear function of current and past signals:

$$
c_{t}=f\left(g\left(s_{t}, s_{t-1}, \ldots\right)\right)
$$

Combining Equations (2.5) and (2.6), we can rewrite the signal process as $s_{t}=(1+$ $\rho) a_{t-1}-\rho a_{t-2}+\epsilon_{t}+v_{t}$. We can notice that both shocks - supply and noise shocks - affect the signal. Moreover, both shocks affect the signal in the same way:

$$
\frac{\partial s_{t}}{\partial \epsilon_{t}}=\frac{\partial s_{t}}{\partial v_{t}}
$$

For the same size shock, the signal will increase by the same amount. As consumption is a linear function of the signal, consumption will also respond in the same way to both shocks:

$$
\frac{\partial c_{t}}{\partial \epsilon_{t}}=\frac{\partial c_{t}}{\partial v_{t}}
$$

In other words, on impact consumers respond in the same way to supply and noise shocks, as they only observe the increase in the signal and are not able to differentiate between the two shocks.

This implies that running a VAR model with consumption and the signal results in a singular system. Moreover, if we extended our model with additional observables, such as stock prices, consumer sentiment or growth forecasts, this would not help to identify 
the shocks. In particular, as long as those observables are a linear function of the signal, we will have:

$$
\frac{\partial x_{t}}{\partial \epsilon_{t}}=\frac{\partial x_{t}}{\partial v_{t}}
$$

The result was also shown in Blanchard et al. (2013) where they offer additional intuition: consumers could use a VAR as a representation of the model, as a VAR model only uses present and past data and consumers have a full knowledge of the economy, except that they do not perfectly observe technology. Assuming the econometricians could identify the two shocks by applying a VAR model to observables, consumers could do the same in the model, and, as a result, the signal extraction problem would disappear.

To show the problems related to the use of a VAR model in practice, we perform the following exercise: we use simulated data to estimate a non-singular VAR model with consumption and the signal by adding a measurement error to the signal. ${ }^{4}$ Supply and noise shocks are identified by theoretically consistent long-run restrictions: the technology shock is identified as a shock with permanent effects on consumption and the noise shock is a shock with only transitory effects.

The impulse responses of consumption to those shocks are plotted in Figure 2, which shows that such an approach is not able to correctly identify the two shocks, as already shown in Blanchard et al. (2013). While the first shock is permanent, it does not build up slowly, as with our theory-based technology shock, but jumps on impact. Similarly, the identified transitory shock is expected to be a mixture of the measurement error and the theoretical noise shock. Figure 2 shows that, unlike the permanent supply shock, consumption does not respond at all to the identified transitory shock.

\footnotetext{
${ }^{4}$ The measurement error is assumed to be a white noise process with $\mathcal{N}\left(0,0.0001 \sigma_{v}^{2}\right)$.
} 
Figure 2: Impuse responses of consumption to supply and noise shocks
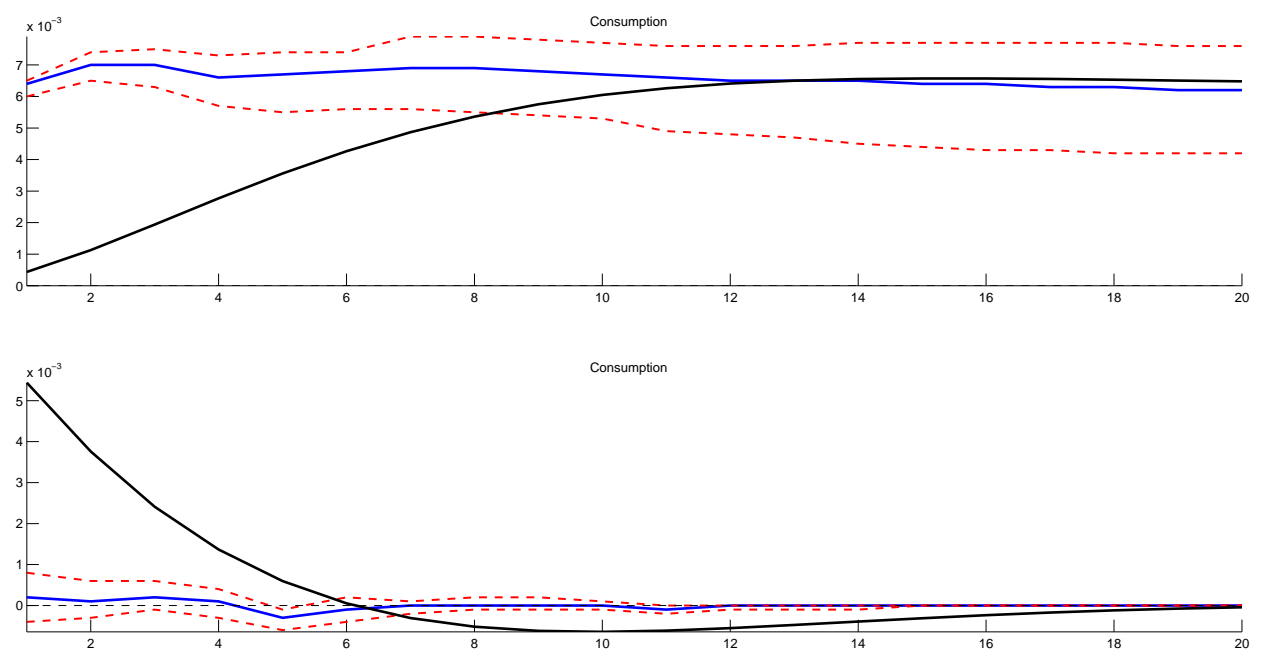

The graph presents the estimated impulse responses of consumption to a supply (above) and a noise (below) shock. The black lines are theoretical responses. The blue line is the point estimate and the red lines are $90 \%$ error bands.

The above principles do not hold for the reaction of consumption in later periods. In other words, we observe that:

$$
\frac{\partial s_{t+j}}{\partial \epsilon_{t}} \neq \frac{\partial s_{t+j}}{\partial v_{t}} \quad \forall j=1,2, \ldots \quad \rightarrow \quad \frac{\partial c_{t+j}}{\partial \epsilon_{t}} \neq \frac{\partial c_{t+j}}{\partial v_{t}} \quad \forall j=1,2, \ldots
$$

As consumers begin to differentiate between the two shocks, via the Kalman filter, the response of consumption differs in the periods following the shocks.

\subsection{Consumers vs. Econometricians}

The preceding discussion shows that to identify shocks we have in order to use a superior information set than the one available to consumers. To start with an extreme situation, let us assume that the econometrician has access to the time series of technology and can infer the consumers' forecast error:

$$
\eta_{t}=E_{t}\left[a_{t} \mid \mathcal{I}_{t}\right]-a_{t}
$$

Technology responds differently to the two shocks:

$$
1=\frac{\partial a_{t}}{\partial \epsilon_{t}} \neq \frac{\partial a_{t}}{\partial v_{t}}=0
$$


and since the forecast error is a linear function of technology and the signal, it responds differently to the two shocks:

$$
\frac{\partial \eta_{t}}{\partial \epsilon_{t}} \neq \frac{\partial \eta_{t}}{\partial v_{t}}
$$

This implies that we can use a VAR model to retrieve the noise and the permanent supply shocks:

Proposition 1. A VAR model with consumption and forecast errors exists. Using an appropriate identification scheme, we can exactly identify the permanent supply shock, $\epsilon_{t}$, and the noise shock, $v_{t}$.

Proof. in Appendix in section A.

This result is implicitly used in Forni et al. (2017) to justify the identification of noise shocks, as it also assumed by these authors that potential output is revealed after one or more periods and therefore the econometrician can retrieve forecast errors. Had we assumed that the econometrician has access to forecast errors, for example by observing utilization, we would also be able to exactly identify the shocks.

However, in reality, the econometrician cannot observe the true level of technology and the related forecast errors. In a less extreme situation, we can assume that the econometrician does not have access to perfect information about the state of the economy, but can have access to superior information compared to what is actually observed by the economic agents.

How well can the econometrician approximate the forecast error by using a superior information set, $\mathcal{I}_{t}^{e}$ ? We can define the forecast errors and the econometrician's estimate of the forecast errors as:

$$
\eta_{t}=E_{t}\left[a_{t} \mid \mathcal{I}_{t}\right]-a_{t} \quad \rightarrow \quad \hat{\eta}_{t}=E_{t}\left[a_{t} \mid \mathcal{I}_{t}\right]-E_{t}\left[a_{t} \mid \mathcal{I}_{t}^{e}\right]
$$

In the extreme case described above, the econometricians have perfect information, $E_{t}\left[a_{t} \mid \mathcal{I}_{t}^{e}\right]=a_{t}$, and they can exactly recover the forecast error, $\hat{\eta}_{t}=\eta_{t}$. Note that, in the opposite extreme case, if the econometricians have the same information set as the agents, their estimate of the forecast error is 0 .

With a more plausible situation, there are two ways in which the econometrician can use superior information to achieve a more precise estimate of the state of economy, i.e. achieve $\operatorname{var}\left(E_{t}\left[a_{t} \mid \mathcal{I}_{t}^{e}\right]-a_{t}\right)<\operatorname{var}\left(E_{t}\left[a_{t} \mid \mathcal{I}_{t}\right]-a_{t}\right)$ :

- Using more accurate signals: $\operatorname{var}\left[v_{t} \mid \mathcal{I}_{t}^{e}\right]<\operatorname{var}\left[v_{t} \mid \mathcal{I}_{t}\right]$ 
- Using future observations: $\mathcal{I}_{t} \subset \mathcal{I}_{t}^{e}$

\subsubsection{Using more accurate signals}

In the real world, consumers and firms have to base their decisions on real-time data. As shown for instance by Diebold and Rudebusch (1991), forecast errors tend to be larger when using real-time data compared with those based on revised data.

It can be shown that:

$$
\lim _{\sigma_{v}^{2} \rightarrow 0} E\left[E_{t}\left[a_{t} \mid \mathcal{I}_{t}^{e}\right]-a_{t}\right]=0
$$

which implies that in the limit, when the signal becomes perfectly informative, we can exactly recover the state and the forecast error, $\eta_{t}$. We can also show that:

$$
\sigma_{v}^{2}<\sigma_{v}^{2 *} \rightarrow \operatorname{var}\left[\eta_{t} \mid \sigma_{v}^{2}\right]<\operatorname{var}\left[\eta_{t} \mid \sigma_{v}^{2 *}\right]
$$

which implies that more informative signals help to decrease the forecast error and the more precise the signal, the greater the decrease in the forecast error.

In order to see how more accurate signals help to estimate the forecast error, we run a simulation where consumers have a signal with the baseline variance, $\sigma_{v}^{2}$, while the econometrician can use a signal with a smaller variance to predict the state. The estimate of the forecast error is then constructed as $\hat{\eta}_{t}=E_{t}\left[a_{t} \mid \mathcal{I}_{t}\right]-E_{t}\left[a_{t} \mid \mathcal{I}_{t}^{e}\right]$, where the difference in consumers' and the econometrician's information sets, $\mathcal{I}_{t}$ and $\mathcal{I}_{t}^{e}$, relates to the difference in the variance of the signal.

Table 1 shows how the precision of the estimated forecast error improves when the econometrician has access to a more precise signal. When the signal that the econometrician observes becomes less noisy relative to the signal observed by the consumer (i.e. when the variance of the noise shocks affecting the precision of the signal is becoming smaller for the econometrician relative to the consumer), the correlation between the estimated and the true forecast errors increases rapidly. ${ }^{5}$

\footnotetext{
${ }^{5}$ The contribution of the relative reduction in the variance of the noise shocks - and thus the contribution of the more precise signal for the econometrician compared to the consumer - to the better estimate of the forecast error depends on the correlation between the noise shocks affecting the signal of the econometrician and those affecting the signal of the consumer. If the noise shocks with a lower variance that affect the signal of the econometrician are written as $v_{t}^{*}=a v_{t}$, implying that the correlation between the noise shocks of the econometrician and the consumer is perfect, then the improvement in the signal contributes the most to the better estimate of the forecast error. In this subsection, we assumed that the correlation between the improvement in the signal and the noise shocks is perfect. See also footnote 9 .
} 
Table 1: Correlation between estimated and true forecast errors

\begin{tabular}{cccccc}
\hline & $\sigma_{v}^{2}$ & $0.75 \sigma_{v}^{2}$ & $0.5 \sigma_{v}^{2}$ & $0.25 \sigma_{v}^{2}$ & $0 \sigma_{v}^{2}$ \\
\hline $\operatorname{corr}\left(\eta_{t}, \hat{\eta}_{t}\right)$ & 0 & 0.88 & 0.93 & 0.94 & 1 \\
\hline
\end{tabular}

\subsubsection{Using future observations}

The econometrician can also potentially observe a larger dataset, including 'future' data. By contrast, consumers cannot observe 'future' realizations. If we define $\mathcal{I}_{t}^{e . j}=\left\{s_{t+j}\right.$, $\left.s_{t+j-1}, s_{t+j-2}, \ldots\right\}$, we can show: ${ }^{6}$

$$
\operatorname{var}\left[E_{t}\left[a_{t} \mid \mathcal{I}_{t}^{e .(j+h)}\right]-a_{t}\right]<\operatorname{var}\left[E_{t}\left[a_{t} \mid \mathcal{I}_{t}^{e . j}\right]-a_{t}\right] \forall h=1,2, \ldots
$$

which implies that having access to future signals helps to decrease the forecast error and the more leads are available, the greater the decrease.

In general, future data does not perfectly reveal the true state of technology and therefore the true forecast error, $\eta_{t}$. The gain obtained by using future observations depends on the variance of the signal - the lower the variance of the signal, the greater the improvement in estimation accuracy obtained by including future observations.

We perform another simulation allowing the econometrician to observe different leads of the signal. The forecast error is then estimated as:

$$
\hat{\eta}_{t}=E_{t}\left[a_{t} \mid \mathcal{I}_{t}\right]-E_{t}\left[a_{t} \mid \mathcal{I}_{t}^{e . j}\right]
$$

Table 2 shows how close to the actual forecast errors the estimated forecast error can become when the number of leads increases. With four leads, the correlation between the estimated and the true forecast errors increases to 0.72 .

Table 2: Correlation between estimated and true forecast errors

\begin{tabular}{cccccc}
\hline & 0 leads & 1 lead & 2 leads & 3 leads & 4 leads \\
\hline $\operatorname{corr}\left(\eta_{t}, \hat{\eta}_{t}\right)$ & 0 & 0.44 & 0.58 & 0.67 & 0.72 \\
\hline
\end{tabular}

It is important to note that this improvement in the estimate of $a_{t}$ allows the econometrician to estimate the forecast error. In fact, from the definition of $\hat{\eta}_{t}$, we can see that the econometrician's estimate of the forecast error is equal to their correction of

\footnotetext{
${ }^{6}$ See Simon (2006), page 271.
} 
the estimate of the true state. Such corrections cannot be made by the agents. Thus, we can decompose $\hat{\eta}_{t}$ into a component due to the use of revised data, which we denote by $\hat{\lambda}_{t}$, and a component due to the use of future data, denoted by $\hat{\kappa}_{t} \cdot{ }^{7}$ All the possible differences can be summarized in the following table:

Table 3: Forecast error estimation

\begin{tabular}{lcc}
\hline & Kalman Filter & Kalman Smoother \\
\hline Real time data & Consumers' expectation & $\hat{\kappa}_{t}$ \\
Revised data & $\hat{\lambda}_{t}$ & Econometrician's estimate $\left(\hat{\eta}_{t}\right)$ \\
\hline
\end{tabular}

Using simulated data, Figure 3 shows the estimate of the forecast error using future signals and its difference with the true forecast error. As shown in the lower panel, the estimated forecast error matches the patterns of the actual forecast error and the correlation between the two is relatively high (0.8). Similarly, Figure 4 shows the same graphs for an estimate of the forecast error using a less noisy signal. The correlation between the true forecast error and the estimated one is again high (0.68). ${ }^{8}$ Finally, Figure 5 shows the estimate of the forecast error that combines the previous two estimates. The correlation between this final estimate of the forecast error and the true one is very high (0.89), which supports our strategy.

\footnotetext{
${ }^{7}$ More precisely, $\hat{\kappa_{t}}$, is defined as a difference in the estimate of the state obtained with a Kalman smoother that uses all available information in the sample and a Kalman filter that uses only information up to period $t$.

${ }^{8}$ In the simulation we assume that the standard error of the noise shock is half the standard error of the noise shocks in the baseline. However, contrary to the exercise in Section 3.2.1, we assume zero correlation between the improvements of the signal and the noise shock, implying the gain from more informative signal to be less than in the case of perfect correlation as in Section 3.2.1. See also footnote 8.
} 
Figure 3: An estimate of forecast errors due to the use of future signals $-\hat{\kappa}_{t}$ (simulated data)


The black line represents the true level of technology. The red line represents the expectations that are obtained via a Kalman filter. The blue line represents the expectations that are obtained via a Kalman smoother. The green line represents the difference between the two series of expectations, which is a proxy for the forecast error estimated with the use of future values. The black line represents the true forecast errors. 
Figure 4: An estimate of forecast errors due to the use of less noisy signals $-\hat{\lambda}_{t}$ (simulated data)
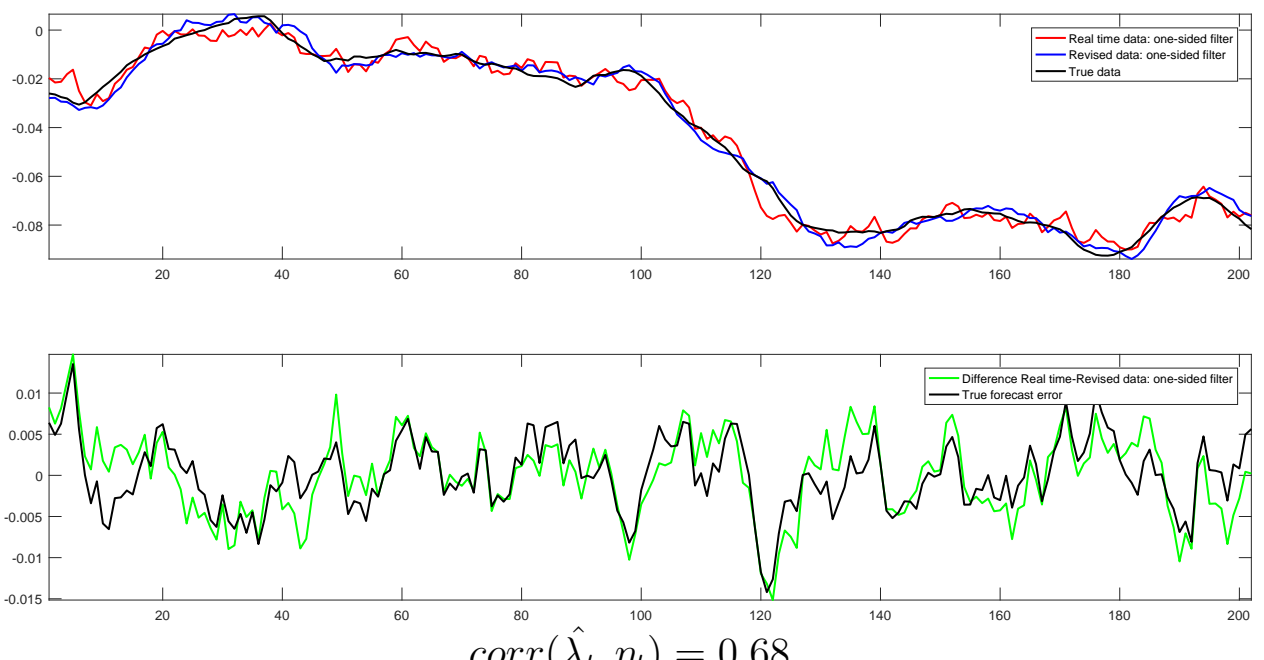

The black line represents the true level of technology. The red line represents the expectations that are obtained via a Kalman filter using the real-time data. The blue line represents the expectations that are obtained via a Kalman filter using the revised data (less noisy signal). The green line represents the difference between the two series of expectations, which is a proxy for the forecast error estimated with the use of revised data. The black line represents the true forecast errors. 
Figure 5: A final estimate of forecast error $-\hat{\eta}_{t}$

(simulated data)
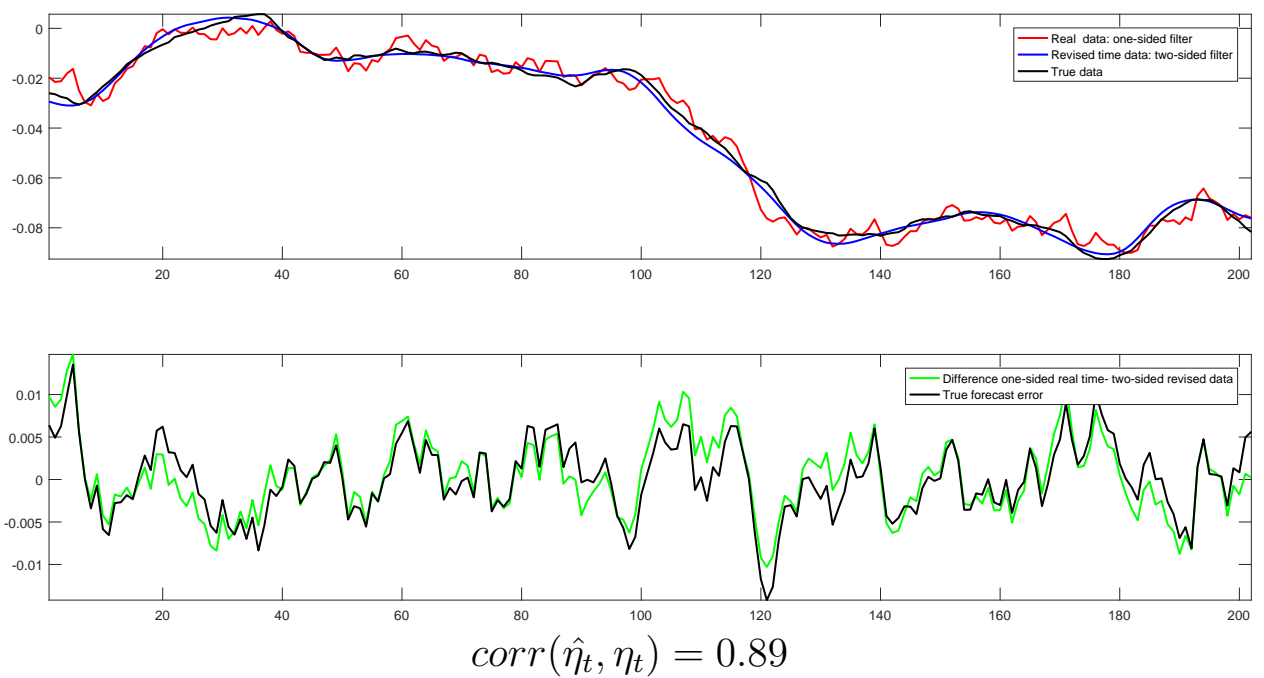

The black line represents the true level of technology. The red line represents the expectations that are obtained via a Kalman filter using the real-time data. The blue line represents the expectations that are obtained via a Kalman smoother using the revised data (less noisy signal). The green line represents the difference between the two series of expectations, which is a proxy for the forecast error estimated with the use of revised data. The black line represents the true forecast errors.

\subsection{Approximation with a VAR model}

We have seen above that we can approximate the forecast error, $\hat{\eta}_{t}$, by using more precise data and future values of the signal. We have also shown that if we had access to the series of forecast errors, $\eta_{t}$, we could use a structural VAR model to obtain the series of noise and supply shocks. Can we still use a VAR model if we replace the original forecast errors by approximated forecast errors?

To answer this question, we estimate a VAR model that includes consumption and instead of the true forecast error, as in Section 2, we use estimates of the forecast errors, $\hat{\eta}_{t}$. The estimates of forecast errors are obtained by using both future observations and more precise signals. ${ }^{9}$

The identification of the shocks is obtained by sign restrictions. From our theoretical model, we know that the forecast error responds negatively to the supply shock and

9 The use of future observations may cause the VAR with forecast errors to be singular. However, when the improvements in the signal are not perfectly correlated with the noise shocks itself, i.e. the newly defined noise shocks with lower variance cannot be written as $v_{t}^{*}=a v_{t}$, the problem of singularity does not appear. The detailed explanation can be found in Appendix B. In the following exercises, we assume that the correlation between the improvements in the signal and the noise shocks is zero. 
positively to the noise shock, while consumption responds positively to both. This implies that we can use the sign restrictions included in Table 4 to identify supply and noise shocks. ${ }^{10}$

Table 4: Imposed sign restrictions

\begin{tabular}{lcc}
\hline & Forecast error & Consumption \\
\hline Supply shock & - & + \\
Noise shock & + & + \\
\hline
\end{tabular}

In the following example, we use a 50 percent less noisy signal and four leads of the signal to produce the econometrician's estimate of the forecast error, $\hat{\eta}_{t}$.

Figure 6 compares the theoretical and the estimated impulse responses to a supply shock (first row) and a noise shock (second row). ${ }^{11}$ The shape and size of the two forecast errors are very similar to the theoretical ones, implying that our sign restriction strategy is now able to distinguish between a supply and a noise shock. The response of consumption to these shocks is also similar to what the theoretical model predicts: after a supply shock, consumption increases gradually and is permanently affected by the shock; after a noise shock, consumption increases only in the short term and returns gradually to the baseline state after a few periods. Figure 7 shows the results of the same exercise by comparing estimated (first row) and theoretical (second row) forecast error variance decompositions (FEVD). The contributions of supply and noise shocks to the forecast error variance are very similar when comparing the estimated and the theoretical decompositions. Noise shocks explain most of the variance of consumption and forecast errors in the short-run, while supply shocks mainly explain the variance of consumption in the long-run.

\footnotetext{
${ }^{10}$ Sign restriction are imposed only on impact.

${ }^{11}$ The simulation is performed 200 times, with time series of length 900 . The standard errors therefore report the uncertainty in reduced-form parameter estimates and identification uncertainty.
} 
Figure 6: Estimated impulse responses by using estimated forecast errors (simulated data)
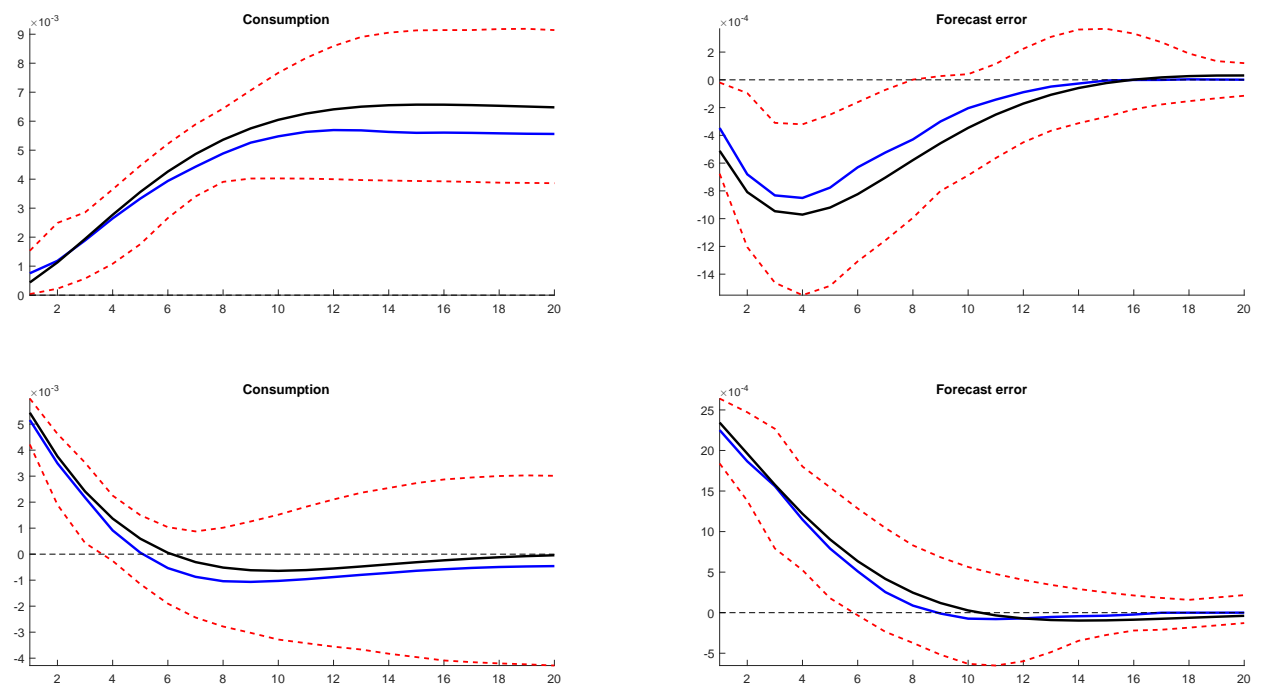

The graph presents the estimated impulse responses of consumption (left) and forecast errors (right) to a supply (above) and a noise (below) shock. The estimated forecast errors are obtained by using 4 leads of the signal and 50 percent less noisy signal. The black lines are theoretical responses. The blue line is the point estimate and the red lines are the $90 \%$ error bands. 
Figure 7: Simulated data: Estimated FEVD (above) and theoretical FEVD (below)


The first row presents the estimated forecast error variance decomposition (FEVD) of consumption (right) and forecast errors (left). The second row presents the theoretical forecast error variance decomposition (FEVD) of consumption (right) and forecast errors (left). The blue area corresponds to the median contribution of the supply shock and the green area corresponds to the median contribution of the noise shock. The estimated forecast errors are obtained by using 4 leads of the signal and 50 percent less noisy signal.

\subsection{Comparison with Forni et al. (2017)}

We can show that the methodology proposed in Forni et al. (2017) cannot be applied to a general signal extraction model as used in this paper and in Blanchard et al. (2013). Moreover, our approach can easily accommodate their methodology. 
To show these points, we remind the two crucial equations of the model in Forni et al. (2017):

$$
\begin{gathered}
a_{t}=a_{t-1}+\varepsilon_{t-1} \\
s_{t}=\varepsilon_{t}+v_{t}
\end{gathered}
$$

where $a_{t}$ is the observable technology, $s_{t}$ is a signal about technology, $\varepsilon_{t}$ is the supply shock and $v_{t}$ is the noise shock. The signal extraction problem comes from the fact that the supply shock has delayed effects on technology $\Delta a_{t}=\varepsilon_{t-1}$. Importantly, contrary to the general model used in this paper, this framework implies that a VAR including the current observable technology and the signal is not singular. This is easy to see as $\frac{\partial s_{t}}{\partial \varepsilon_{t}}=\frac{\partial s_{t}}{\partial v_{t}}$, but $\frac{\partial a_{t}}{\partial \varepsilon_{t}} \neq \frac{\partial a_{t}}{\partial v_{t}}$ and therefore the problem of singularity of the VAR that was discussed in Section 3.1 does not appear in this case.

It is also straightforward to understand why our methodology can be applied to the model described by (3.16) and (3.17). Indeed, using one lead of technology enables to exactly recover the supply shock, $\Delta a_{t+1}=\varepsilon_{t}$. This implies that the estimated forecast error is equal to the true forecast error, $\hat{\eta}_{t}=\eta_{t}$, and the shocks can be exactly recovered.

\section{Empirical evidence on U.S. data}

Given the positive results of the simulations above, we use our methodology to estimate the effects of supply and noise shocks on U.S. data. We first explain how we construct the real-world counterpart of the forecast error. Second, we present the VAR model we use to identify supply and noise shocks. The empirical analysis is performed with two different VAR models. First, we use a small-scale VAR that includes only the forecast error and consumption and corresponds to the one used in the theoretical section. We show that the results are consistent with the predictions of our theoretical model and we show that these results are robust to a different identification strategy.

In the next subsection, we extend the VAR model with additional variables. The main reasons to extend the VAR is that many shocks other than "animal spirits" can be compatible with a small set of restrictions used in the small-scale VAR model. Moreover, the larger model allows us to study the effects of noise shocks on other variables, like output, stock prices, interest rates and inflation. The sign restrictions of our larger model are based on the predictions resulting from the structural model of Hürtgen (2014). 


\subsection{Constructing forecast errors}

The first step in the empirical application is to construct the forecast error about the state of the economy. The relevant state variable in the model is technology. However, although it would be possible to exactly map the model to the empirical applications by assuming technology as the relevant state, we opt for using potential GDP as the relevant state of the economy in the empirical application.

The main reason behind this choice is that real-time data for productivity does not exist, except in the case of output per hour worked in the business sector, which is anyway only available since $1998 .{ }^{12}$ Moreover, potential GDP, rather than technology, is a more important piece of information on which firms, public sector and consumers focus when making economic decisions. Indeed, trend GDP is regularly estimated by public institutions, forecasted by professional forecasters and is also the usual measure of potential output monetary policy authorities typically use when setting monetary policy (Gavin 2012).

The forecast errors about the state of the economy are defined as follows:

$$
\hat{\eta}_{t}=\frac{\widehat{y p}_{t}^{\text {realtime }}-\widehat{y p}_{t}^{\text {final }}}{\widehat{y p}_{t}^{\text {final }}}
$$

where $\widehat{\eta}_{t}$ is the estimated forecast error, $\widehat{y p}_{t}^{\text {realtime }}$ is the estimated potential output in real time and $\widehat{y p}_{t}^{\text {final }}$ is the final estimate of potential output. To construct real-time and final estimates of potential output we rely on two approaches. While in the benchmark exercise we use publicly available information on real-time and final estimates of potential output, we estimate, as robustness check, real-time and revised potential output through an unobserved component model similar to what has been described in our theoretical model.

In the benchmark case, the forecast error is constructed from the actual/official estimate provided by the $\mathrm{CBO}$ and a real-time estimate of potential GDP. To compute our estimate of real-time potential GDP, we use the real-time estimate and projections of the output gap available in the Greenbook ${ }^{13}$ and add it to the real-time level of GDP. 'Standard' real-time data - the first estimates of GDP available in period $t$ from statistical offices - is normally available only after at least one quarter. In order to be consistent with the model, we have to construct the measure of real GDP in period $t$ that was

\footnotetext{
${ }^{12}$ See https://www.philadelphiafed.org/research-and-data/real-time-center/real-time-data/datafiles/OPH/

${ }^{13}$ See https://www.philadelphiafed.org/research-and-data/real-time-center/greenbook-data
} 
available exactly in period $t$. To this end, we use GDP forecasts for the current period from the Survey of Professional Forecasters.

The real time data for real GDP, $y_{t}^{r t}$, is constructed as:

$$
y_{t}^{r t}=y_{t-1}^{*}\left(1+\Delta \hat{y}_{t}\right)
$$

where $y_{t-1}^{*}$ is the first estimate of real GDP in period $t-1$ as provided by the statistical office (for details on construction see Appendix C) and $\Delta \hat{y}_{t}$ is the forecast for the quarterly real GDP growth rate in period $t$ as produced by the Survey of Professional Forecasters.

\subsection{Small-scale VAR model}

We start our empirical analysis with a small-scale VAR model that includes the estimated forecast error and real consumption. The estimated forecast errors are those defined in the previous subsection. The estimation period is from Q3 1987 to Q4 2011, imposed by the availability of data on real-time estimate of output gap from the Greenbook. The system is estimated using the level of forecast errors and the log of consumption with 8 lags.

\subsubsection{Identification}

The identification of supply and noise shocks can be achieved in two ways. Firstly, we can impose sign restrictions that are based on the different response of the forecast error to the supply and noise shocks. The second way is to rather use the behavior of consumption - we know that noise shocks should lead to a transitory response of consumption, while supply shocks should affect consumption permanently. Therefore, we can identify the supply and noise shocks by imposing long-run restrictions à la Blanchard and Quah (1989).

We start by identifying the two shocks by sign restrictions. From the theoretical model we know that:

- The forecast error is positive for positive noise shocks (i.e. consumers are too optimistic).

- The forecast error is negative for positive supply shocks (i.e. consumers are too pessimistic). 
We also know that consumption will increase following both shocks. Hence, the same sign restrictions as in Table 4 are used to separate the noise from the supply shock. Restrictions are imposed over one year. In Section 5, we perform as a robustness check an exercise imposing restrictions only in a first period in our large-scale VAR.

To cross-check whether the results are robust to alternative identification strategy, we also use long-run restrictions proposed in Blanchard and Quah (1989). In particular, the noise shock is identified by imposing transitory effects on consumption, while the supply shock has permanent effects on consumption. In a small-scale VAR model with only consumption and the forecast error, we identify the permanent and transitory shocks to consumption using the following restrictions on the matrix of long-run effects, $\Xi$ :

$$
\Xi=\left[\begin{array}{ll}
* & 0 \\
* & *
\end{array}\right]
$$

implying the second shock does not have permanent effects on consumption and therefore can be considered as a noise shock in our setup.

\subsubsection{Empirical results - sign and long-run restrictions}

Figure 8 shows the impulse responses of consumption and the forecast error to a noise shock, using the sign restriction methodology described above. The estimation algorithm is described in Appendix D. The impacts are positive and significant in the short run (up to 10-15 quarters). Once the consumer realises that the shock is not related to an improvement in productivity, the forecast error returns to 0 and the impact on consumption becomes non-significant. Figure 9 shows the impulse responses of the same variables following a supply shock. As imposed, the impact on the forecast error is negative in the short run, while the impact on consumption is limited. Over time, as the consumer realizes that the shock is a permanent supply shock, the forecast error returns to 0 and consumption improves permanently.

To cross-check these results with the identification strategy based on long-run restrictions, we perform again the same IRFs (see Figures 10 and 11). The responses are qualitatively similar to those obtained with the sign restriction approach. In particular, without imposing the sign restrictions, we again find that a positive permanent supply shock implies negative forecast errors in the short term, while a positive transitory noise shock increases the forecast error, being in this case positive. 
Figure 8: Small-scale VAR - Impulse reponses to a noise shock (sign restrictions)
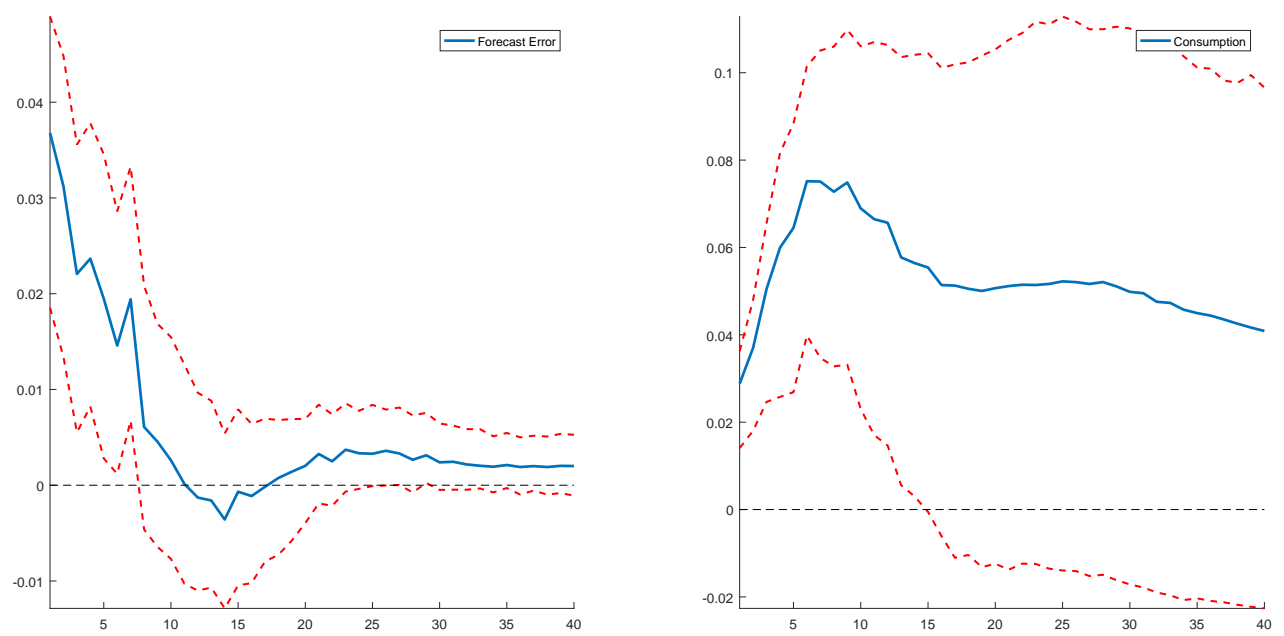

The graph presents the impulse responses to a noise shock of the estimated forecast error and consumption. The blue line is the point estimate and the red lines are the $68 \%$ error bands.

Figure 9: Smal-scale VAR - Impulse reponses to a supply shock (sign restrictions)
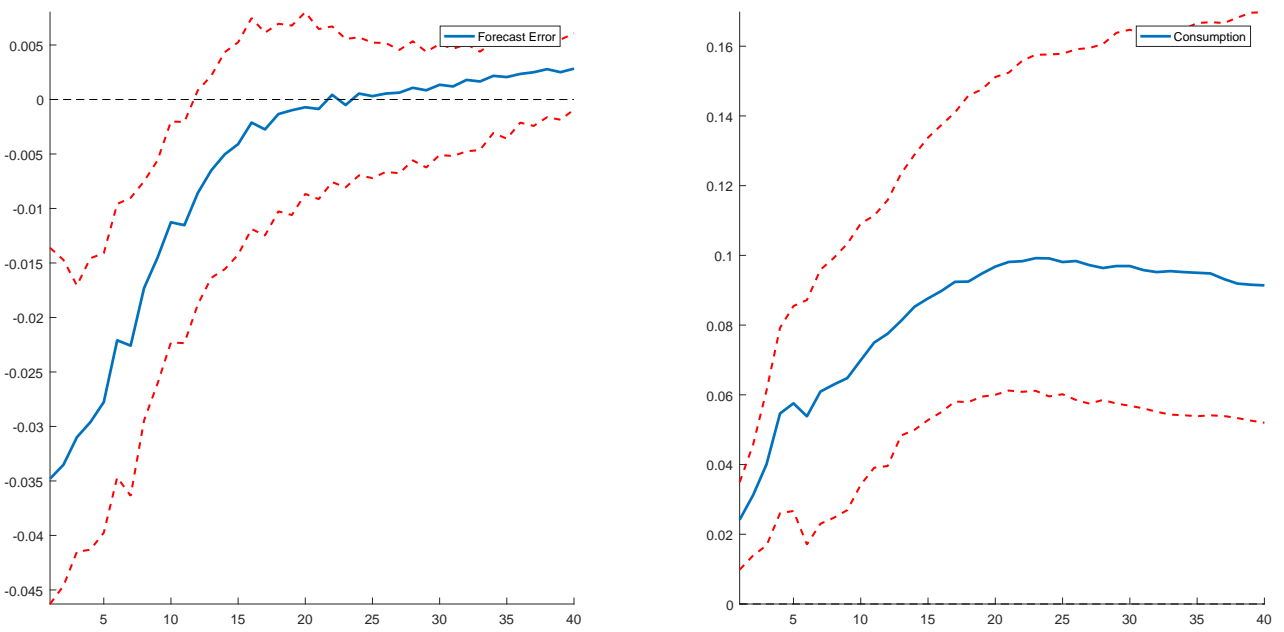

The graph presents the impulse responses to a supply shock of the estimated forecast error and consumption. The blue line is the point estimate and the red lines are the $68 \%$ error bands. 
Figure 10: Smal-scale VAR - Impulse reponses to a noise shock (long-run restrictions)
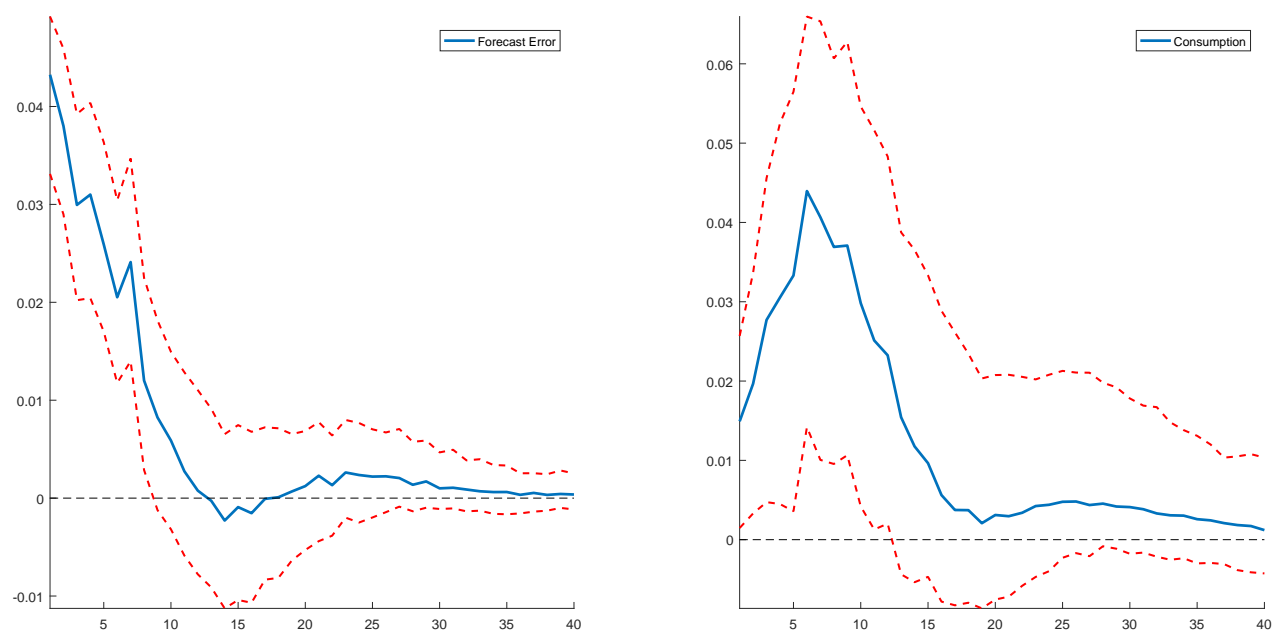

The graph presents the impulse responses to a noise shock of the estimated forecast error and consumption. The blue line is the point estimate and the red lines are the $68 \%$ error bands.

Figure 11: Small scale-VAR - Impulse reponses to a supply shock (long-run restrictions)
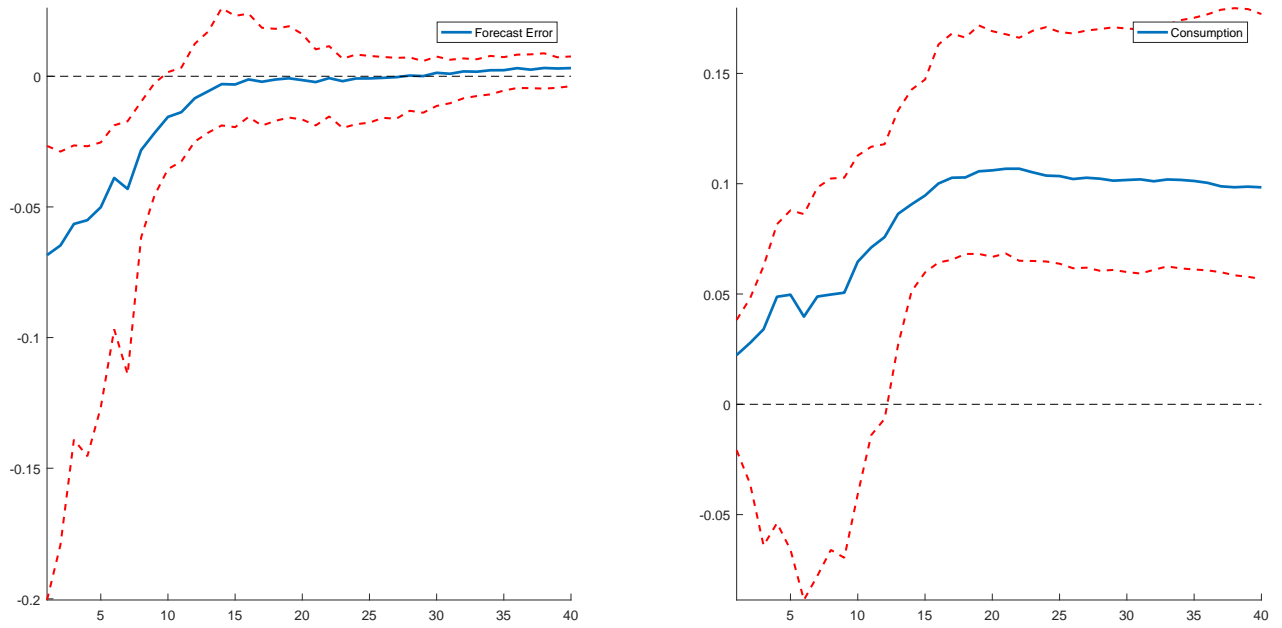

The graph presents the impulse responses to a supply shock of the estimated forecast error and consumption. The blue line is the point estimate and the red lines are the $68 \%$ error bands. 


\subsection{Large-scale VAR model}

The small-scale VAR model used in the previous section has been used to test our theoretical model on data. However, it might not be empirically appealing, as it uses too little information from the data. Moreover, with a two-variable VAR, we assume that only two structural shocks drive the data. Therefore, in this section we enrich the VAR model by including additional variables and add additional identifying restrictions that rely on a larger structural model as described in Hürtgen (2014). The extended setup allows us to identify possible additional sources of shocks and see the impact of noise shocks on additional variables, such as stock prices or consumer sentiment. The extended VAR model includes the following variables:

- Estimated Forecast Errors (FE)

- GDP (Y)

- Private Consumption $(\mathrm{C})$

- Investment (I)
- Stock prices (S\&P500 - SP)

- Consumer Sentiment (SENT)

- Fed funds rate (IR)

- CPI inflation (INF)

The definition and sources of the data are detailed in Table 5

Table 5: Statistical sources of the data

\begin{tabular}{lcc}
\hline Variable & Definition & Source \\
\hline FE & See Section 4.1 & Philadelphia Fed and authors' calculations \\
Y & Real GDP & U.S. Dept of Commerce (NIPA) \\
C & Real Pers. Cons. Exp. & U.S. Dept of Commerce (NIPA) \\
I & Real Gross Private Domestic Investment & U.S. Dept of Commerce (NIPA) \\
SP & S\&P 500 Stock Price Index & Standard and Poor's \\
IR & Effective Federal Funds Rate & Board of Governors of the Fed. Reserve System \\
INF & Quarterly change in CPI (All Items) & U.S. Dept of Labor (Bureau of Labor Stat.) \\
SENT & Index of Consumer Sentiment & Surveys of Consumers (Univ. Michigan) \\
\hline
\end{tabular}

The sample size is from Q3 1987 to Q4 2011, except Estimated Forecast Errors from Q3 1989 to Q4 2011.

The estimation period is still from Q3 1987 to Q4 2011. The system is estimated in log-levels with four lags, except for forecast errors, inflation rate and interest rate that enter in level. 


\subsubsection{Identification}

The main identification assumption to separate the noise and the permanent supply shocks is similar to the section above - we use sign restrictions on the forecast errors and consumption to separate the two shocks. As the VAR model includes more variables, we also use the results of the model by Hürtgen (2014) to base our sign restrictions. In his work, Hürtgen (2014) includes imperfect information as in Lorenzoni (2009) into a Smets and Wouters (2007)-type DSGE model. Like in our theoretical model, agents only observe a signal of aggregate productivity and a signal about the permanent component contaminated with noise. The predictions based on this model allow us to enrich the restrictions of our small-scale VAR model by restrictions on other variables. In particular, Hürtgen (2014) find that noise shocks, through beliefs of higher productivity, increase output, consumption, inflation and nominal interest rates. We use these predictions as restrictions to our large-scale VAR model and impose them over one year. Results with sign restrictions imposed only in the first period are commented in Section 5. The beliefs in higher productivity translate in our setting into a positive forecast error. In addition, we impose also that sentiment increases following the noise shock. However, the results are robust when dropping this restriction, except that the share of sentiment explained by both shocks goes down (results can be obtained on request). It is worth noting that the results are also robust whether or not restrictions are imposed on nominal interest rates. As with our small-scale VAR model, we compare these results with standard supply shocks, which differ from noise shocks by their negative impacts on forecast errors and inflation. Exact restrictions are summarized in Table 6:

Table 6: Imposed sign restrictions

\begin{tabular}{lcccccccc}
\hline & FE & Y & C & I & SP & SENT & IR & INF \\
\hline Supply shock & - & + & + & + & & + & & - \\
Noise shock & + & + & + & + & & + & & + \\
\hline
\end{tabular}

\subsubsection{Empirical results}

We start our empirical exercise with impulse response functions (IRFs). Figure 12 shows the IRFs following a 1-standard deviation positive noise shock. In this case, the forecast error increases and remains significantly positive for around two years. As expected by the theoretical model, the impact on output and consumption is also positive for around 
10 quarters, returning thereafter to baseline. Private investment, equity prices and sentiment are also affected positively and reach their peak impact after a few quarters before returning gradually to baseline. We can also observe that the response of investment to a noise shock is somewhat smaller and reacts with a lag, compared to consumption or sentiment. Inflation and interest rates also increase on impact and remain significantly positive for around a year.

Figure 13 shows impulse response functions (IRFs) following a 1-standard deviation positive supply shock. Although we only impose sign restrictions in the short term, the technology shock implies permanent effects on macroeconomic variables, as expected from our theoretical model. Indeed, output and consumption are permanently higher. Private investment also benefits from the positive supply shock and the impulse responses remain significantly different from zero at long horizons. As expected from theory, the forecast error is significantly negative for 10 quarters, before returning towards the baseline. Inflation declines on impact but is not permanently affected. Interestingly, the increase in equity prices and consumer sentiment following the supply shock is rather long lasting.

We perform next forecast error variance decompositions (FEVD). Figure 14, shows that the noise shock explains 25 percent of business cycle fluctuations in the short term. As expected from theory, the impact of the supply shock on the business cycle builds up gradually. It also explains up to 20 percent of output variations at business cycle frequencies and around a third of fluctuations in the long term, when the noise shock contribution becomes much smaller. It is worth noting that the noise shock explains a large share of fluctuations in consumption in the short term (around 30 percent), showing the impact of forecast errors made by consumers on their expenditure behaviors. Private investment and stock price fluctuations are also influenced to a large extent by noise shocks in the short term.

Finally, Figure 15 shows the series of extracted shocks (5-quarter moving average), with supply shocks in the upper panel and noise shocks in the lower panel. ${ }^{14}$ The patterns between these two shocks are very different. A few interesting observations are worth pointing out. First, the supply shock declines just before recessions and increases during the three recessions of our sample, which could be interpreted as a Schumpeterian creative-destruction mechanism driving the recovery phase. Second, the noise shock was very positive during the dot-com bubble in the early 2000s and went down when optimism about future technologies was affected by the 2001 terrorist attacks, the Enron scandal

\footnotetext{
${ }^{14} \mathrm{We}$ use a centered 5-quarter moving average of shocks in order to better capture the pattern of shocks.
} 
and the stock market decline in 2001-02. Noise shocks increased again thereafter to reach another high just before the house price bubble burst in 2007. Third, noise shocks tend to remain negative for a prolonged period of time during and after a recession, underlining the role of excess pessimism as a dampening factor in the recovery phases. Similarly, noise shocks were very negative during the global financial crisis in 2009. Finally, the fall in noise shocks in the mid-1990s could be explained by the fact that current and anticipated expansion was actually driven by supply factors, as shown by positive supply shocks. This is in line with observed strong economic growth, steady job creation, low inflation and rising productivity that partly resulted from rapid technological changes.

Figure 12: Large-scale VAR - Impulse responses to a noise shock
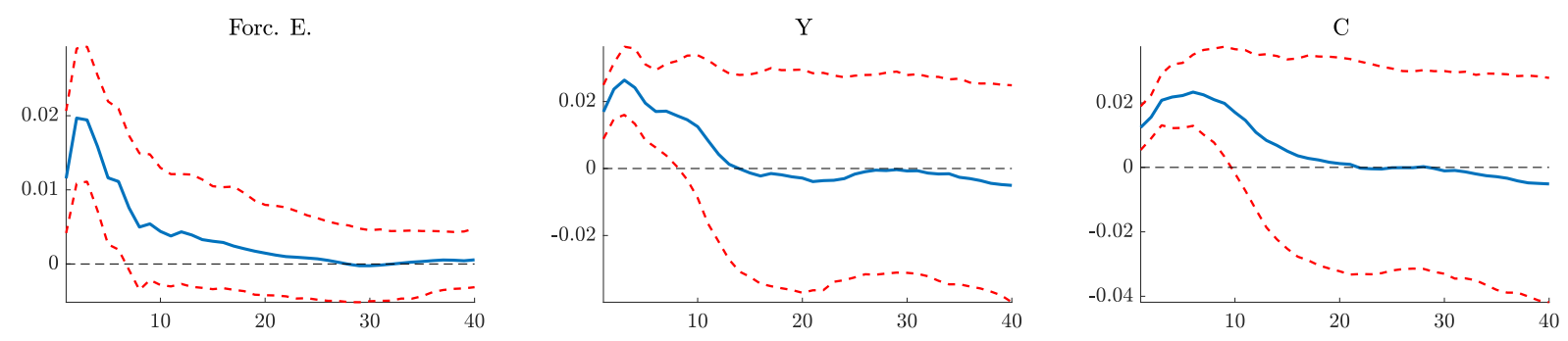

I

SP
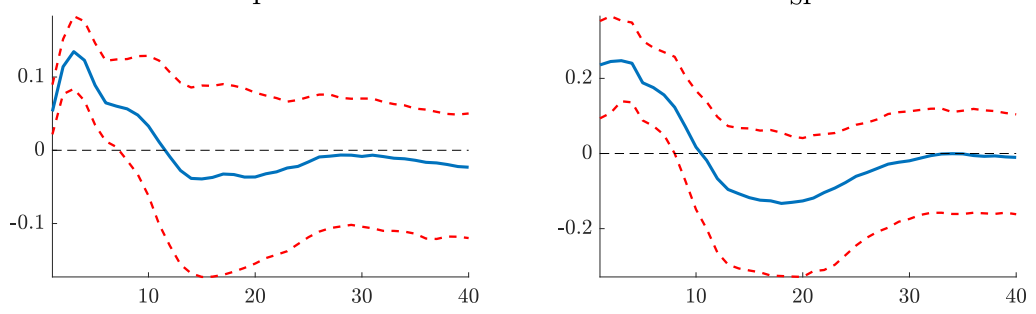

SENT

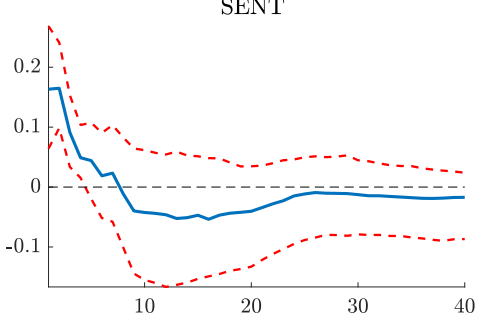

IR


The graph presents the impulse responses to a noise shock of the estimated forecast error, output and consumption (first row), investment, stock prices and sentiment (second row) and interest rates and inflation (third row). The blue line is the point estimate and the red lines are the $68 \%$ error bands. 
Figure 13: Large-scale VAR - Impulse responses to a supply shock
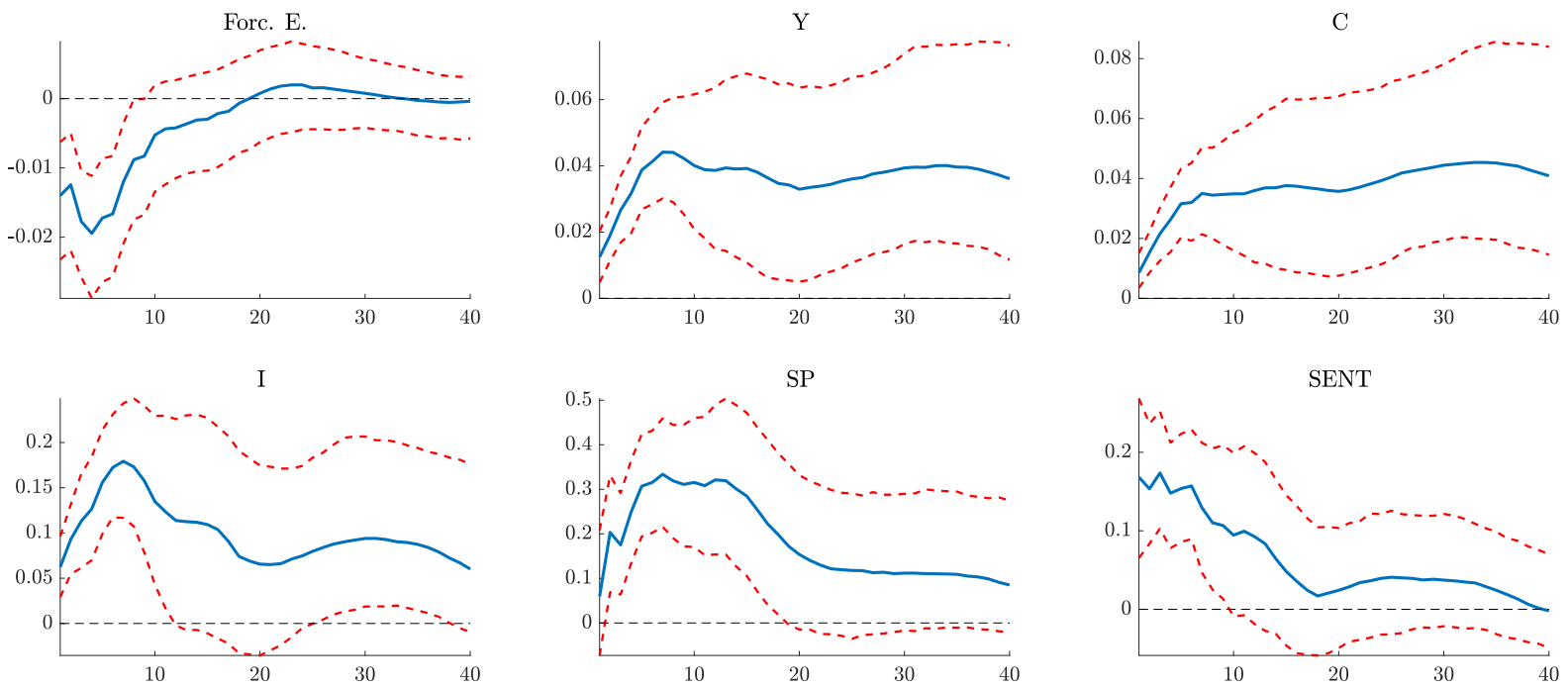

IR
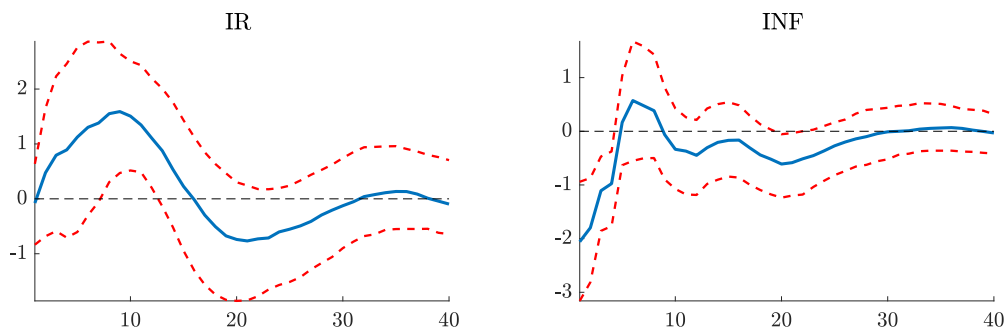

The graph presents the impulse responses to a supply shock of the estimated forecast error, output and consumption (first row), investment, stock prices and sentiment (second row) and interest rates and inflation (third row). The blue line is the point estimate and the red lines are the $68 \%$ error bands. 
Figure 14: Large-scale VAR - Forecast Error Variance Decomposition

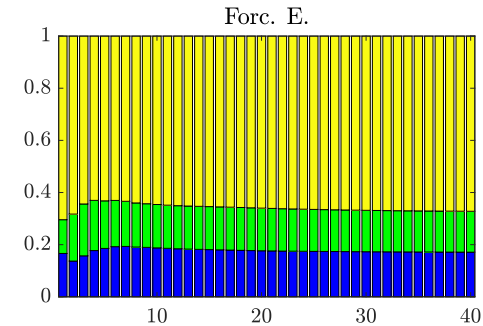

I



IR

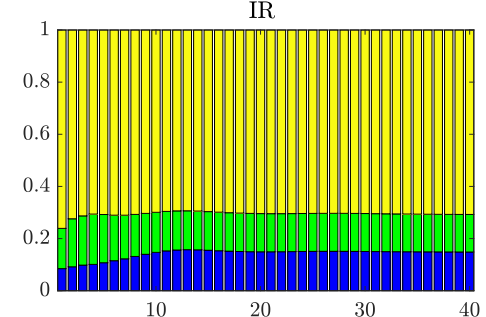

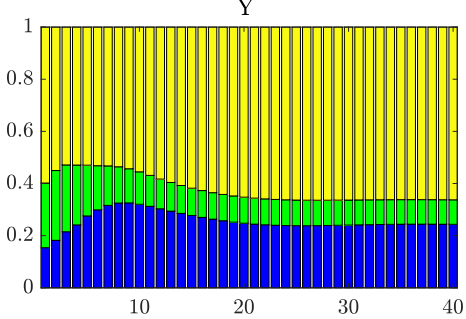

SP

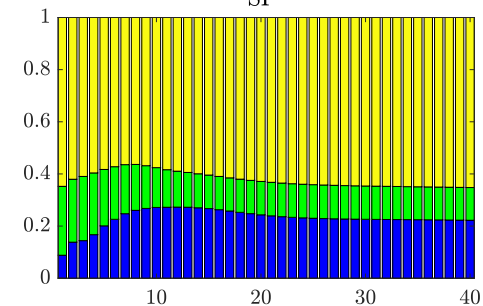

INF

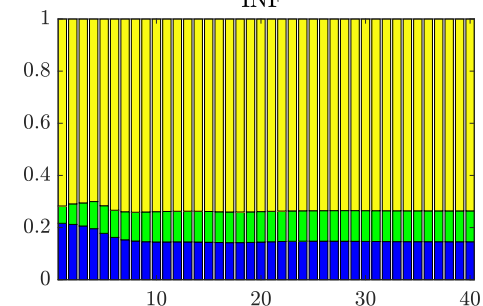

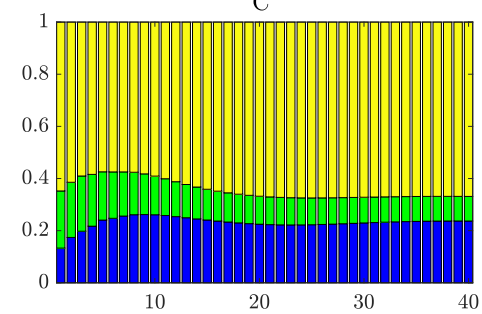

SENT

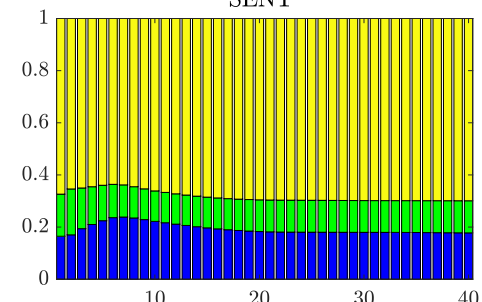

$10 \quad 20$

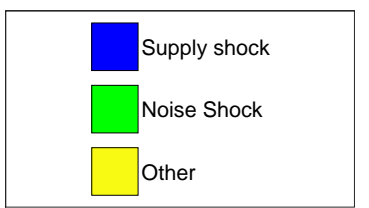

The graph presents the forecast error decomposition of the estimated forecast error, output, consumption (first row), investment, stock prices and sentiment (second row) and interest rates and inflation (third row). The blue area corresponds to the median contribution of supply shocks, the green area to the median contribution of noise shocks and the yellow area to the contribution of all other non-identified shocks. 
Figure 15: Large-scale VAR - extracted shocks (5-quarter centered moving average)
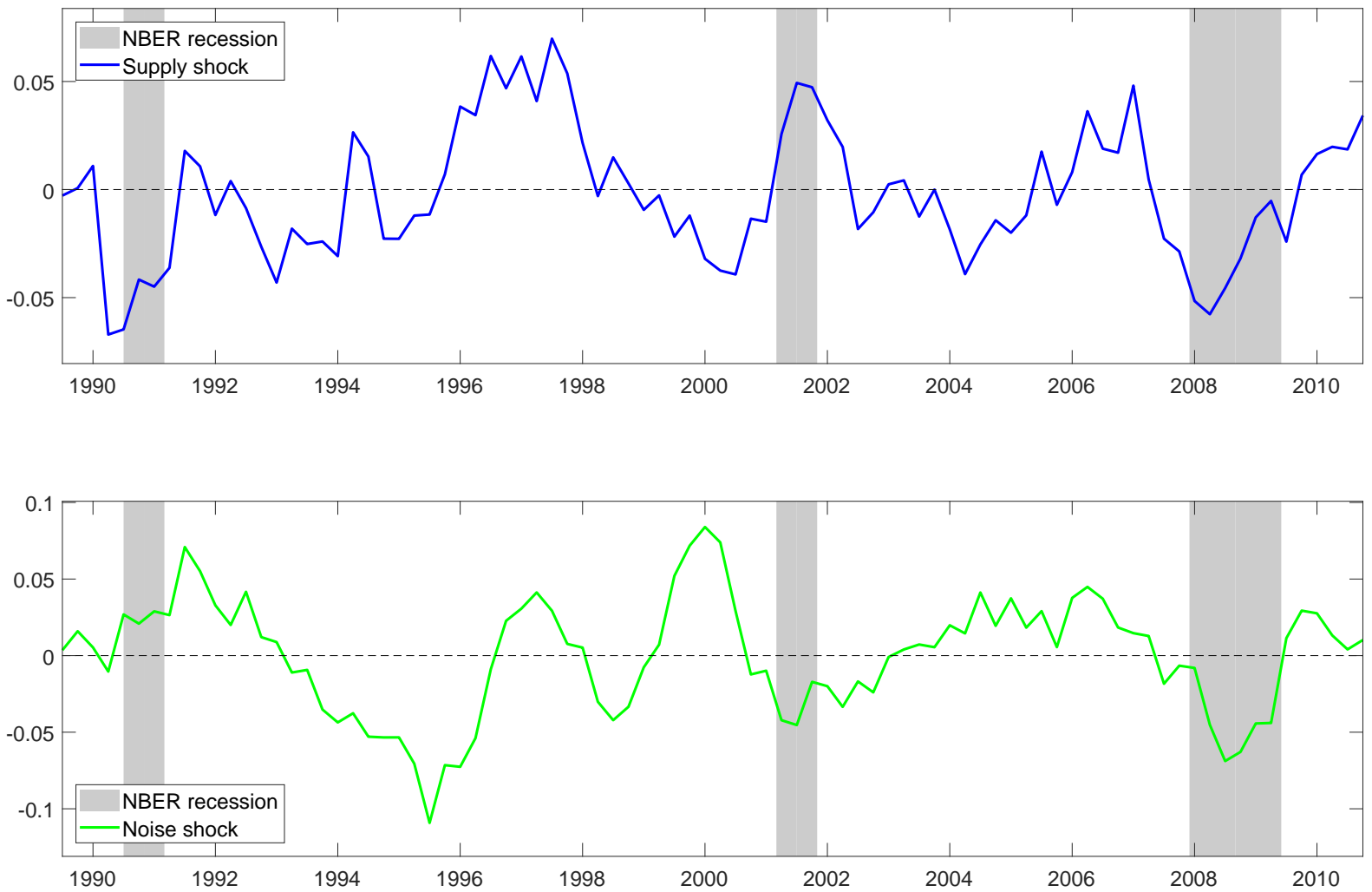

The graph presents the extracted supply (blue line above) and noise shocks (green line below). The series of shocks are smoothed with moving average filter with a 5-period window. The gray areas correspond to NBER-defined recessions.

\section{Robustness checks}

To confirm the robustness of our results we perform three additional exercises. First, instead of constructing the forecast error from real time data from the Greenbook and revised data from $\mathrm{CBO}$, we estimate forecast errors by using a similar filter to the one used in the theoretical section. Secondly, we check whether our results are robust to imposing the restrictions for a quarter only (instead of a year). Third, while noise shocks have so far been interpreted as micro-founded demand shocks as in Lorenzoni (2009), we also entertain the case of noise shocks being supply driven.

\subsection{Alternative Forecast Error}

In this subsection, we use an alternative approach to calculate the forecast errors that does not rely on published real-time estimates of potential output. We rather estimate 
the forecast errors ex-post using a similar model as in our theoretical section. As we do not need to rely on relatively short historical data, this method allows us to extend our sample to 1970Q1-2012Q2. ${ }^{15}$

\subsubsection{Estimating the forecast error}

Instead of using the real-time data from the Greenbook and the revised data from the $\mathrm{CBO}$, we use an alternative way to estimate the forecast errors by relying on the filter detailed in the theoretical part. This implies estimating potential GDP with an unobserved component model that can be written as follows:

1. State Equation

$$
\left[\begin{array}{c}
\tau_{t \mid t} \\
\tau_{t-1 \mid t}
\end{array}\right]=\left[\begin{array}{cc}
1+\rho & -\rho \\
1 & 0
\end{array}\right]\left[\begin{array}{c}
\tau_{t-1 \mid t-1} \\
\tau_{t-2 \mid t-1}
\end{array}\right]+\left[\begin{array}{ll}
1 & 0 \\
0 & 0
\end{array}\right]\left[\begin{array}{c}
\epsilon_{t} \\
0
\end{array}\right]
$$

2. Observation Equation

$$
y_{t}=\left[\begin{array}{ll}
1 & 0
\end{array}\right]\left[\begin{array}{c}
\tau_{t \mid t} \\
\tau_{t-1 \mid t}
\end{array}\right]+\left[\begin{array}{ll}
0 & 1
\end{array}\right]\left[\begin{array}{c}
0 \\
\eta_{t}
\end{array}\right]
$$

where $\epsilon_{t} \sim \mathcal{N}\left(0, \sigma_{\epsilon}^{2}\right)$ and $\eta_{t} \sim \mathcal{N}\left(0, \sigma_{\eta}^{2}\right)$. In this model $y_{t}$ is real GDP, $\tau_{t}$ is its trend component, $\eta_{t}$ is its cyclical component and $\epsilon_{t}$ is a white noise sequence. Normalizing the variance of the noise component to one, $\sigma_{\eta}^{2}=1$, we can write the signal-to-noise ratio as $\zeta=\frac{\sigma_{\eta}^{2}}{\sigma_{\epsilon}^{2}}$. To calibrate the two parameters of the filter, $\rho$ and $\zeta$, we minimize the distance between the state estimate of potential output using (5.1) with the estimate of potential output by the Congressional Budget Office (CBO). The minimization results in setting $\rho=1$ and $\zeta=2221 .^{16}$

Once we have parameterized the state-space system, we can estimate the forecast error in the same fashion as explained in Section 3.2. The correspondence between the model and the empirical application can be summarized as follows:

- Use of future data - Consumers only use past data and determine trend GDP with a Kalman filter, which is a one-sided filter. The econometrician can also use

\footnotetext{
${ }^{15}$ The sample starts in 1968Q4 and we drop 5 observations at both ends of the sample to account for the bias in the estimation of the forecast error at the beginning and at the end of the sample.

${ }^{16}$ We have restricted the autoregressive coefficient $\rho$ to one, as coefficients higher than one would imply the consumer behavior in the theoretical model not to be well defined. We thank an anonymous referee for pointing this out. The unrestricted minimization results in setting $\rho=1.04$ and $\zeta=2808$.
} 
'future' data when filtering the GDP series with a Kalman smoother, which is a two-sided filter. ${ }^{17}$

- Better signal - Consumers can only use real-time data. The econometrician, having access to revised data, uses more accurate information about the state in a given period.

Figure 16 shows the final estimate of forecast errors and its decomposition into the component due to the use of future signals and the one due to the use of less noisy signals. We can see that the forecast errors are pro-cyclical: they are positive and increase in the expansion phase, peak at the start of a recession (as defined by the NBER) and then fall, reaching a minimum around two years after the end of the recession phase. A positive, rising error can then be interpreted as an increase in consumers' optimism up to the end of the expansion phase. The error becomes negative during the recession and stays negative as long as consumers remain pessimistic about the economy, thus underpredicting the actual state of the economy.

\footnotetext{
${ }^{17}$ We have also experimented with a Kalman filter that includes 4 forward leads of data instead of using a Kalman smoother. The results were not much affected by this.
} 
Figure 16: A final estimate of forecast errors - $\hat{\eta}_{t}$

(US data)
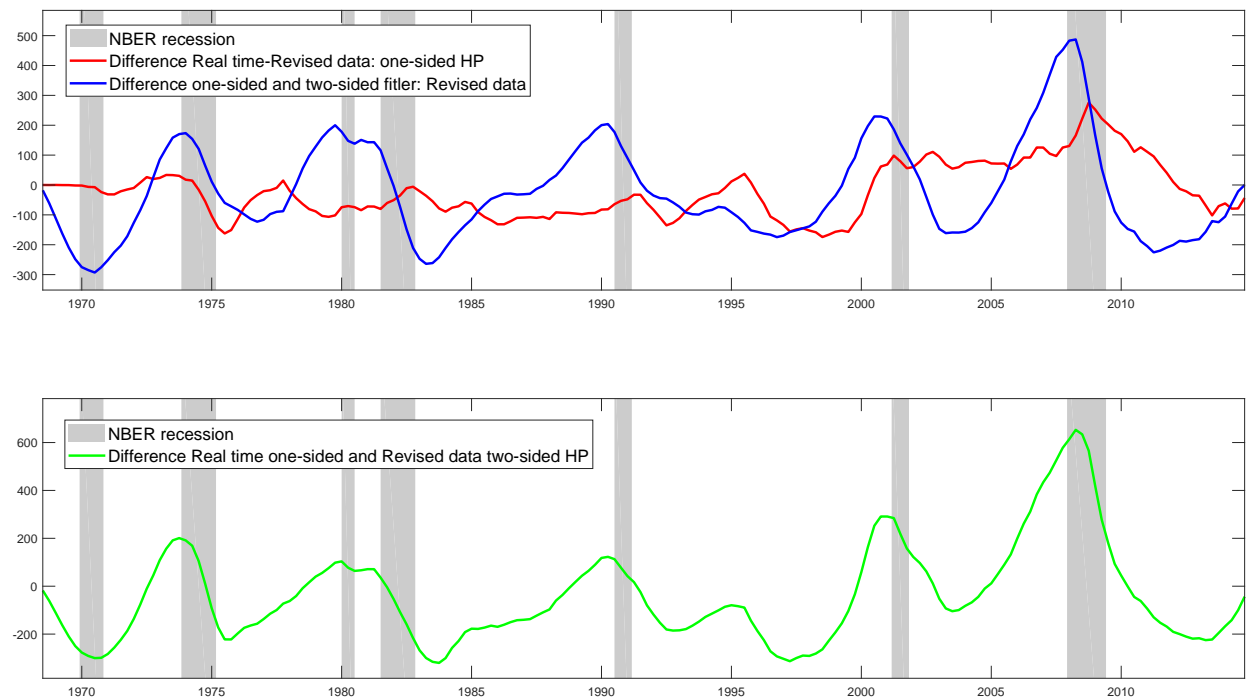

The red line represents the difference in the estimate of the trend GDP that is obtained via a Kalman filter using revised or real-time data, $\hat{\lambda_{t}}$. The blue line represents the difference in the estimate of trend GDP obtained via a Kalman smoother or using a Kalman filter with revised data, $\hat{\kappa_{t}}$. The green line in the bottom panel represents the (joined) difference between the two estimated trends, which is the final estimate of forecast errors, $\hat{\eta}_{t}$. Correlations between the three series are: $\operatorname{corr}\left(\hat{\eta}_{t}, \hat{\lambda_{t}}\right)=0.49$ and $\operatorname{corr}\left(\hat{\eta_{t}}, \hat{\kappa_{t}}\right)=0.92$.

\subsubsection{Results with estimated forecast errors}

Figures 17 and 18 show the impulse responses of noise and supply shocks. Overall, the results found before are confirmed by this alternative approach. In the case of the noise shock, the impact on the forecast error is also positive as expected, but slightly more persistent than with the benchmark approach based on available data. By contrast, the impacts on consumption are significant only for a year, while it lasted for 10 quarters in the benchmark case. The other variables react similarly to the benchmark case, although they generally tend to be slightly larger and more significant. The impulse responses corresponding to supply shocks are also very similar to those shown previously, confirming the robustness of the results found earlier. The FEVD is also similar (see Figures 19), the only notable difference is the larger contribution of the noise shock to changes in the forecast errors, interest rates and inflation. 
Figure 17: Large-scale VAR - Impulse responses to a noise shock
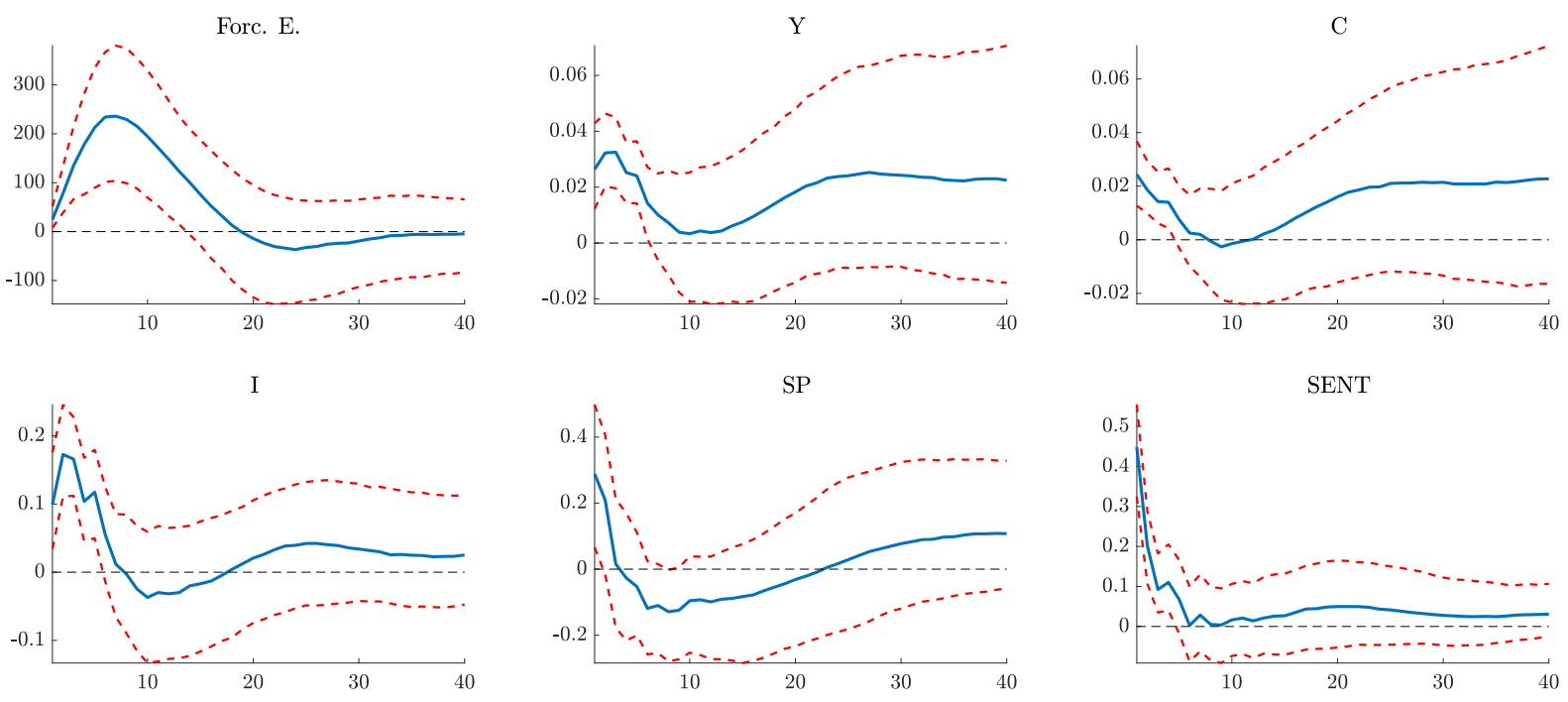

SP



SENT
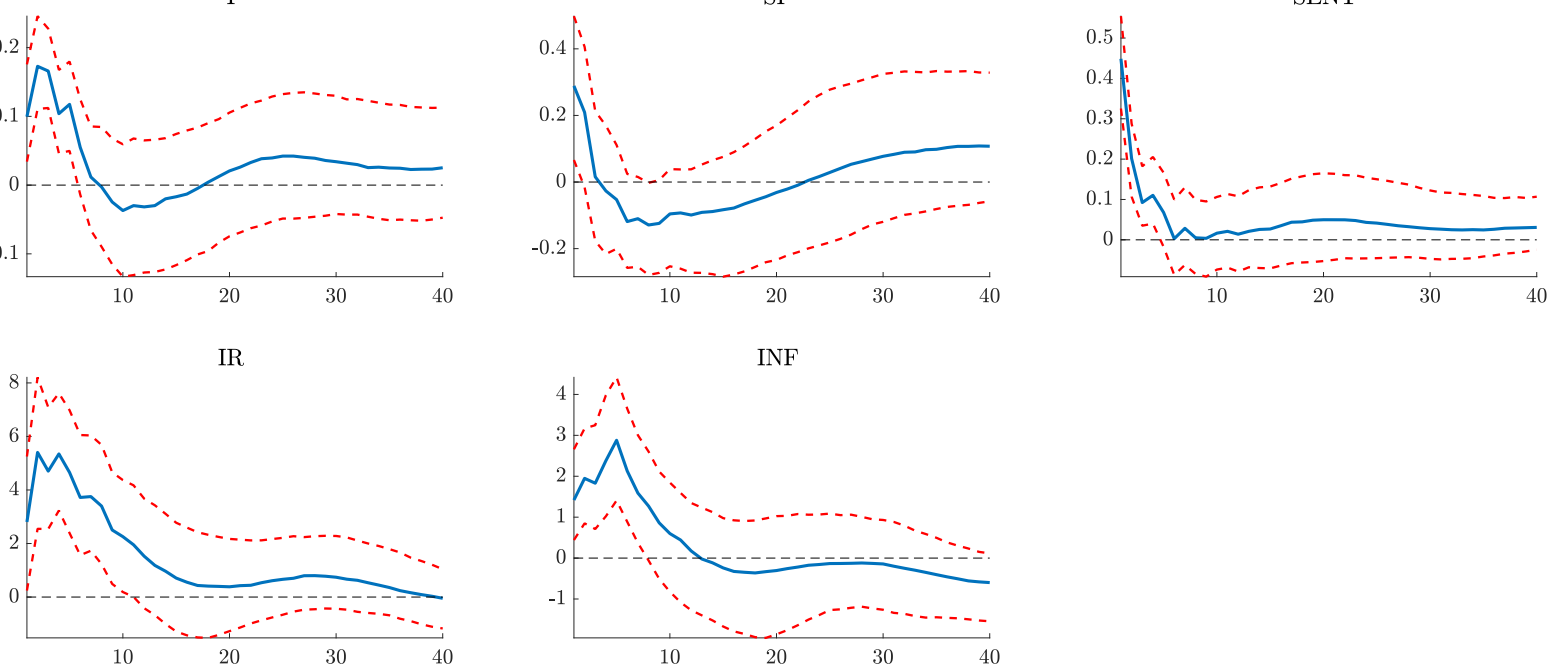

The graph presents the impulse responses to a noise shock of the estimated forecast error, output and consumption (first row), investment, stock prices and sentiment (second row) and interest rates and inflation (third row). The blue line is the point estimate and the red lines are the $68 \%$ error bands. 
Figure 18: Large-scale VAR - Impulse responses to a supply shock
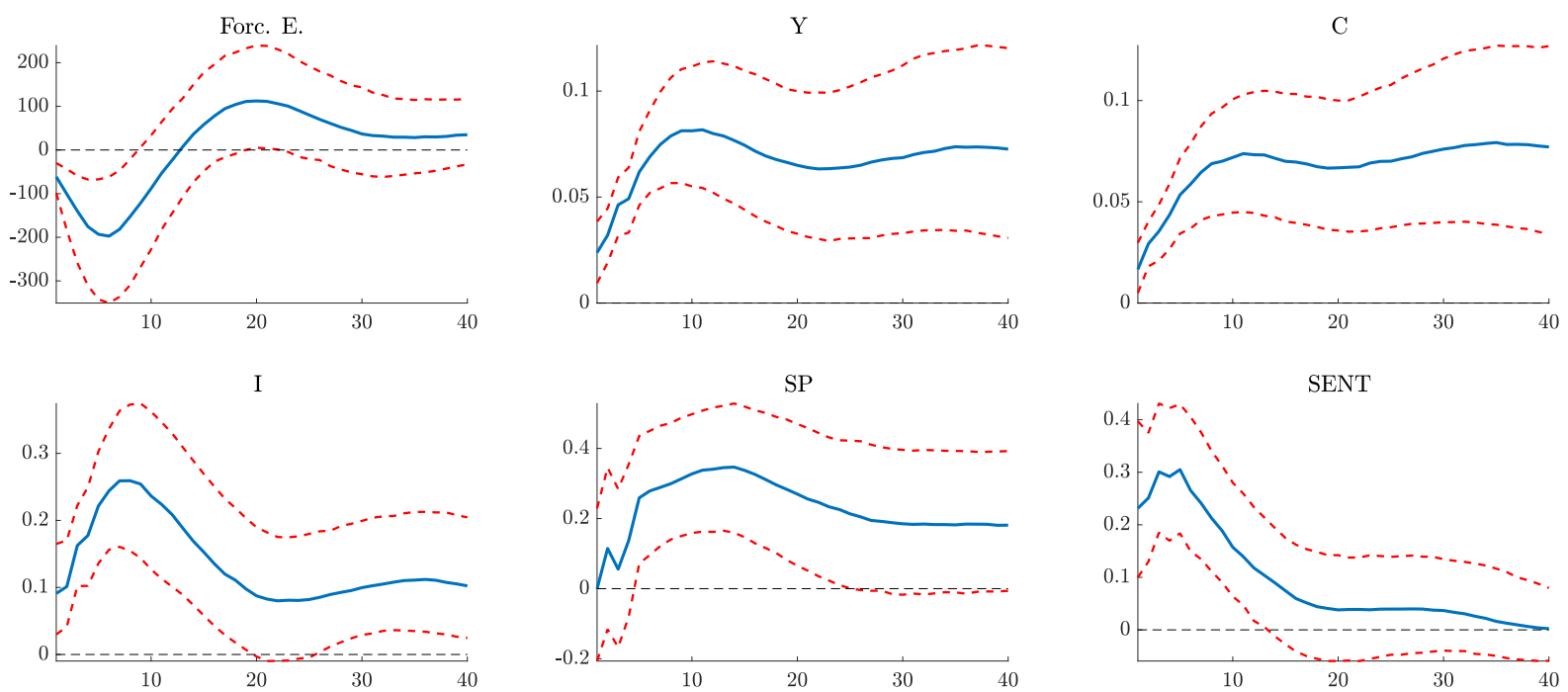

IR
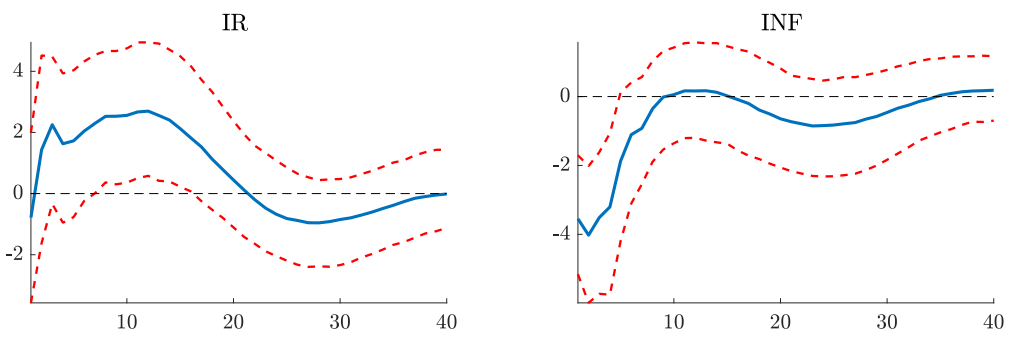

The graph presents the impulse responses to a supply shock of the estimated forecast error, output and consumption (first row), investment, stock prices and sentiment (second row) and interest rates and inflation (third row). The blue line is the point estimate and the red lines are the $68 \%$ error bands. 
Figure 19: Large-scale VAR - FEVD

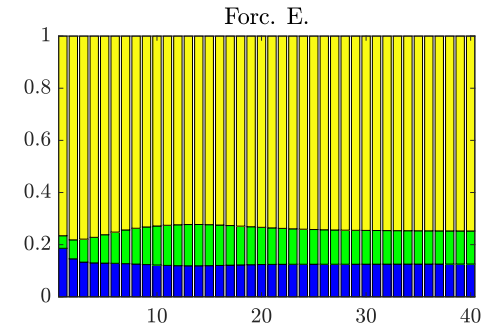

I

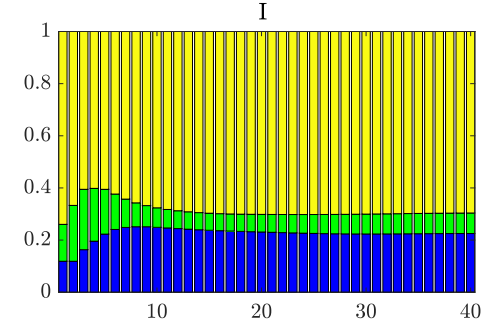

IR

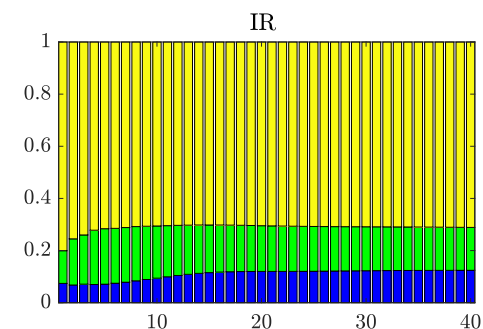

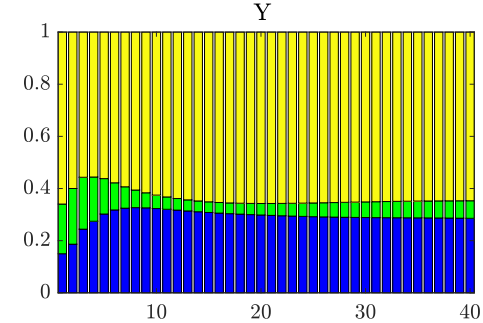

SP

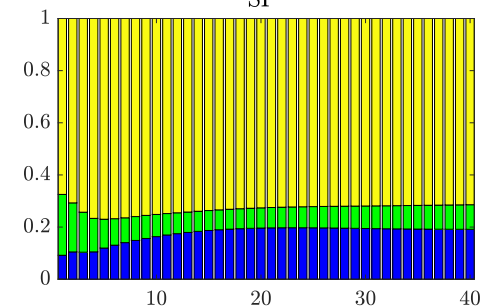

INF

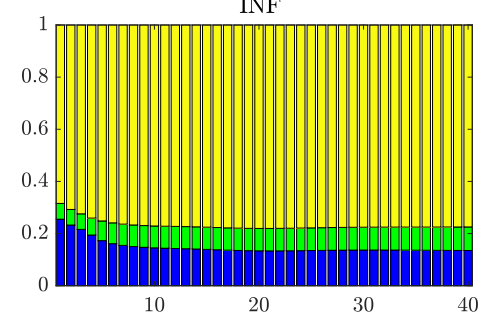

$\mathrm{C}$

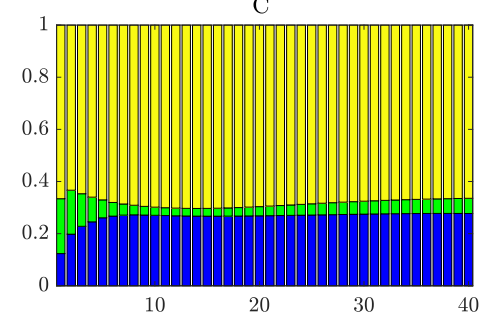

SENT



The graph presents the forecast error decomposition of estimated forecast error, output, consumption (first row), investment, stock prices and sentiment (second row) and interest rates and inflation (third row). The blue area corresponds to the median contribution of supply shocks, the green area to the median contribution of noise shocks and the yellow area to the contribution of all other non-identified shocks.

\subsection{Other robustness checks}

Two other robustness checks have also been performed. For the sake of brevity, we include only the IRFs, but the other corresponding figures are available upon request. First, we impose our sign restrictions over one quarter only and not a full year. As can be seen from Figure 1 and 2 in Appendix E the results remain qualitatively the same, although the impulse responses tend to be significant for a few quarters only in the case of the noise shock. For the supply shock, the impulse responses are almost identical to the benchmark case. As far as the forecast error variance decomposition is concerned, no differences are noticeable, except the contribution of the noise shock to consumption, which is lower compared to the benchmark case.

The second robustness check exercise modifies the identification of the noise shock and considers noise shocks as supply-side shocks. In this case, a noise shock implies the 
same restriction as in Table 6 except that the sign on inflation is negative. Consistent with the idea that noise and supply side shocks could not be differentiated in the first period, we then entertain the case where firms receive a noisy signal about technology and set their price lower in anticipation of higher productivity. This decline in prices is temporary and prices return to baseline once the firms have realized that the signal was noisy. Except the impact on inflation, the impulse responses are very similar to those shown in the benchmark case. The FEVD shows slightly lower contributions of the noise shock to output and consumption fluctuations in the very short term, but these contributions increase thereafter and are even higher than in the benchmark case for medium-term horizons ( 2 to 3 years).

Finally, we use an alternative method for taking into account modeling and parameter uncertainty as proposed by Fry and Pagan (2011). Using a median target method does not qualitatively affect our results, as can be seen from Figures 3 and 4 in Appendix E. If anything, the median based on this method suggests that noise shocks explain an even higher proportion of the variance in output, consumption, investment and stock prices.

\subsection{Comparison with related literature}

Our results correspond to a large extent with those found in the related literature. In particular, most papers that study the effects of noise versus supply shocks find that noise shocks could be interpreted as demand shocks and contribute to a large extent to economic fluctuations at the business cycle frequency. Noise shocks are therefore more important in explaining business cycles compared to permanent or technology shocks.

Blanchard et al. (2013) estimate a structural model and find that noise shocks account for more than $50 \%$ of short-run volatility of consumption, while permanent technology shocks play a smaller role, having almost no effect on quarterly volatility and explaining less than $30 \%$ at a 4 -quarter horizon. Similar to this paper, they find spells of positive permanent shocks in the first half of 1980s and second half of 1990s. While they estimate a structural model, thus putting structure on the data that can have important effects on the final results, we opted for a more parsimonious VAR model. The smoothed series of noise shocks seem therefore more informative in our case, as we obtain a clearer pattern of positive noise shocks before recessions and negative noise shocks at the start and during recessions. Nevertheless, they also find a succession of negative noise shocks around the recession in the early 1990s, and a spell of positive noise shocks before the 2001 recession. ${ }^{18}$

\footnotetext{
${ }^{18}$ They do not find similar patterns before the 2007 recession, as they only use data until 2008.
} 
Results in Forni et al. (2017) are also similar to those found in our paper. The responses of output and consumption have similar shapes. In the case of the noise shock, the responses are hump-shaped with a relatively small, although significant, impact effect; they reach a maximum after about two years and then decline towards zero after about five years. As predicted by the model, noise shocks spur a wave of private consumption and investment which vanishes once economic agents realize that the signal was just noise. They find that the responses to real shocks are permanent, although real shocks sometimes do not have significantly permanent effects as in our paper.

Enders et al. (2013) use a similar empirical strategy to our paper, but they use forecast errors for GDP, which is available only at a later date compared to the initial estimates by agents. They also compare results based on first-release and revised data. Nevertheless, they also find that forecast errors react as predicted by theory, as we found in the exercise in Section 4.2.2. Similarly Benhima and Poilly (2017) explore the same idea in a New Keynesian model and use their model's predictions to identify empirically fundamental and noise shocks on supply and demand. They also find that noise shocks contribute substantially to business cycles. However, given that in both papers the authors only use forecast errors for GDP to improve the estimates of the state, the distinction between permanent productivity shocks and transitory optimism shocks is not as evident as in this and other studies which use potential output.

Barsky and Sims (2012) found the most contrasting results compared to this and other papers in the literature. They find that "animal spirits" effects are very weak and thus account for essentially none of the relationship between confidence and future consumption or income. The reason for such contrasting results is mostly related to the different methodologies - they estimate a structural model by matching theoretical impulse responses with empirical impulse responses. As discussed above, estimating a structural model imposes a structure on the data that may have important effects on the empirical results. While they find noise shocks to be unimportant, they find that permanent shocks are the main drivers of business cycles, especially at longer horizons.

Finally, Angeletos et al. (2014) provide a model with only two sources of volatility: the usual technology shock and a confidence shock that drives the agents' beliefs about the state of the economy. The confidence shock therefore has a similar interpretation to our noise shock. Interestingly, although they use a different model, they also find that confidence shocks can account for a large share of GDP volatility at business-cycle frequencies and that their effects look, as in this paper, similar to a standard demand shock. 


\section{Conclusion}

This paper has presented a model in which consumers receive noisy signals about future economic fundamentals. In this model, business cycle fluctuations can be driven both by news shocks (supply or technology shocks) and noise shocks ("animal spirits" shocks). We have shown that standard structural VAR models cannot be applied in principle to this model to identify the two types of shocks, as the VAR model faces invertibility issues. In other words, if consumers cannot distinguish between the two shocks, the econometrician also faces the same problem. However, by considering that the econometrician can potentially have a richer and more accurate information set, we have shown that a standard structural VAR model can recover both supply and noise shocks. Richer information sets relate to the fact that the econometrician has access to revised data (while consumers take decisions with real-time data) and can include "future" data when estimating the state of the economy (while consumers take decisions with past and current data only).

In the empirical exercise, we have shown that the identified shocks have macroeconomic impacts that are in line with theoretical predictions. We have also shown that noise shocks explain a significant share of business cycle fluctuations in the short term, while supply shocks explain most of output variations in the long term. We have also shown that technology shocks turn negative a few years before recessions, while noise shocks are very positive at the cycle peaks and remain negative for some time during recovery phases. The recovery from recessions is mostly led by technology shocks, following Schumpeterian creative-destructive dynamics. These results are robust to the size of the VAR model and to the identification scheme. Finally, we have shown that consumption is even more affected by noise shocks than output at business cycle frequencies, showing the extent to which false perceptions about future fundamentals play a role in consumers' behaviors.

\section{References}

Angeletos, G.-M., Collard, F., and Dellas, H. (2014). Quantifying Confidence. NBER Working Papers 20807, National Bureau of Economic Research, Inc.

Bacchetta, P., Tille, C., and van Wincoop, E. (2012). Self-fulfilling risk panics. American Economic Review, 102(7):3674-3700. 
Barsky, R. B. and Sims, E. R. (2012). Information, animal spirits, and the meaning of innovations in consumer confidence. American Economic Review, 102(4):1343-77.

Beaudry, P. and Portier, F. (2006). Stock prices, news, and economic fluctuations. The American Economic Review, 96(4):1293-1307.

Benhima, K. and Poilly, C. (2017). Do misperceptions about demand matter? theory and evidence. Cahiers de recherches economiques du département d'econométrie et d'economie politique (deep), Université de Lausanne, Faculté des HEC, DEEP.

Blanchard, O. J., L'Huillier, J.-P., and Lorenzoni, G. (2013). News, noise, and fluctuations: An empirical exploration. American Economic Review, 103(7):3045-70.

Blanchard, O. J. and Quah, D. (1989). The Dynamic Effects of Aggregate Demand and Supply Disturbances. American Economic Review, 79(4):655-673.

Diebold, F. X. and Rudebusch, G. D. (1991). Forecasting output with the composite leading index: A real-time analysis. Journal of the American Statistical Association, 86(415):603-610.

Enders, Z., Kleemann, M., and Müller, G. (2013). Growth expectations, undue optimism, and short-run fluctuations. CESifo Working Paper Series 4548, CESifo Group Munich.

European Central Bank (2013). Confidence indicators and economic developments. Monthly Bulletin, 45(58).

Farmer, R. E. (2012). The stock market crash of 2008 caused the great recession: Theory and evidence. Journal of Economic Dynamics and Control, 36(5):693-707.

Fernández-Villaverde, J., Rubio-Ramrez, J. F., Sargent, T. J., and Watson, M. W. (2007). ABCs (and Ds) of Understanding VARs. American Economic Review, 97(3):1021-1026.

Forni, M., Gambetti, L., Lippi, M., and Sala, L. (2017). Noisy News in Business Cycles. American Economic Journal: Macroeconomics, 9(4):122-152.

Fry, R. and Pagan, A. (2011). Sign Restrictions in Structural Vector Autoregressions: A Critical Review. Journal of Economic Literature, 49(4):938-960.

Hürtgen, P. (2014). Consumer misperceptions, uncertain fundamentals, and the business cycle. Journal of Economic Dynamics and Control, 40:279-292. 
Jaimovich, N. and Rebelo, S. (2009). Can news about the future drive the business cycle? American Economic Review, 99(4):1097-1118.

Keynes, J. M. (1936). General theory of employment, interest and money. Palgrave Macmillian.

Lorenzoni, G. (2009). A theory of demand shocks. American Economic Review, 99(5):2050-84.

Masolo, R. M. and Paccagnini, A. (2018). Identifying Noise Shocks: a VAR with Data Revisions. Journal of Money, Credit and Banking, forthcoming.

Pigou, A. C. (1929). Industrial fluctuations. Macmillan.

Rubio-Ramirez, J. F., Waggoner, D. F., and Zha, T. (2010). Structural Vector Autoregressions: Theory of Identification and Algorithms for Inference. Review of Economic Studies, 77(2):665-696.

Simon, D. (2006). Optimal state estimation: Kalman, H infinity, and nonlinear approaches. Wiley.com.

Smets, F. and Wouters, R. (2007). Shocks and Frictions in US Business Cycles: A Bayesian DSGE Approach. American Economic Review, 97(3):586-606.

Uhlig, H. (2005). What are the effects of monetary policy on output? results from an agnostic identification procedure. Journal of Monetary Economics, 52(2):381-419. 


\section{A Appendix - Proof of proposition from Section 3}

Proposition 1. A VAR with consumption and forecast errors exists. Using an appropriate identification scheme, we can exactly identify the permanent shock, $\epsilon_{t}$, and the noise shock, $v_{t}$.

Proof. The solution of DSGE model can be written in a state-space form as:

1. State Equation:

$$
x_{t}=A_{22}(\omega) x_{t-1}+A_{21}(\omega) \varepsilon_{t}
$$

2. Observation Equation:

$$
y_{t}=A_{11}(\omega) x_{t}+A_{12}(\omega) \varepsilon_{t}
$$

where $x_{t}$ is a vector of state variables, $y_{t}$ is a vector of observable variables, $\varepsilon_{t}$ is a vector of structural shocks and $A_{i i}(\omega)$ are matrices that depend on the model's parameters, $\omega$.

The VAR representation of the state-space system is:

$$
y_{t}=A_{11}\left(1-\left(A_{22}-A_{21} A_{12}^{-1} A_{11}\right) L\right)^{-1} A_{21} A_{12}^{-1} y_{t-1}+A_{12} \varepsilon_{t}
$$

and the moving-average representation is:

$$
y_{t}=\left(I-\left(A_{11}\left(1-\left(A_{22}-A_{21} A_{12}^{-1} A_{11}\right) L\right)^{-1} A_{21} A_{12}^{-1}\right) L\right)^{-1} A_{12} \varepsilon_{t}
$$

We have to show that $A_{12}$ and $\left(I-\left(A_{11}\left(1-\left(A_{22}-A_{21} A_{12}^{-1} A_{11}\right) L\right)^{-1}\right.\right.$ are invertible. The condition for $A_{12}$ to be invertible is that we have the same number of shocks as observable variables, which is the case.

The representation in (A.1) and (A.2) assumes that states are observables. When the states are not observable, as in the present model, they are obtained by Kalman filtering using observables:

$$
\hat{x}_{t}=\left(A_{22}-\mathcal{K} A_{11}\right) \hat{x}_{t-1}+\mathcal{K} \hat{y}_{t}
$$

where $\mathcal{K}$ is a Kalman gain that depends on structural parameters. Using (A.5) and (A.2) we get:

$$
y_{t}=A_{11} \hat{x}_{t}+u_{t}
$$

where $u_{t}=A_{11}\left(x_{t}-\hat{x}_{t}\right)+A_{12} \varepsilon_{t}$.

In order for $\left(I-\left(A_{11}\left(1-\left(A_{22}-A_{21} A_{12}^{-1} A_{11}\right) L\right)^{-1}\right.\right.$ to be invertible, the eigenvalues of $A_{22}-A_{21} A_{12}^{-1} A_{11}$ have to be all less than one in modulus - the conditions implies that 
the errors in predicting the state, $A_{11}\left(x_{t}-\hat{x}_{t}\right)$, should be zero and thus, $u_{t}=A_{12} \varepsilon_{t}{ }^{19}$

Returning to our model, it is clear that forecast errors, $\eta_{t}$, enable us to perfectly reveal the state (technology) as $a_{t}=\hat{a}_{t}+\eta_{t}$. This implies that $u_{t}=A_{12} \varepsilon_{t}$ and that a VAR representation in the signal and forecast errors exists. Using appropriate identification scheme, like long-run restrictions, one can then identify matrix $A_{12}$ and obtain the structural shocks.

\section{B Appendix - Singularity of VAR with leads}

To see the problem related to the singularity of VAR models when the future values of the signals are used, we define an estimate of the state by a Kalman filter as:

$$
\begin{aligned}
\hat{x}_{t}^{t} & =\hat{x}_{t-1}^{t}+\mathcal{K}\left(s_{t}-A \hat{x}_{t-1}^{t}\right) \\
& =(1-\mathcal{K} A) \hat{x}_{t-1}^{t}+\mathcal{K} s_{t}
\end{aligned}
$$

where $\hat{x}_{t}^{t}$ is a state estimate in period $t$ using the signals up to period $t$ - an estimate derived with a standard Kalman filter. $\mathcal{K}$ is the Kalman gain and $s_{t}$ is the signal in period $t$. Similarly, the state estimate in period $t$ using signals up to period $t+1$ can be written as:

$$
\begin{aligned}
\hat{x}_{t}^{t+1} & =\hat{x}_{t-1}^{t+1}+\mathcal{K}^{0}\left(s_{t}-A^{0} \hat{x}_{t-1}^{t+1}\right)+\mathcal{K}^{1}\left(s_{t+1}-A^{1} \hat{x}_{t-1}^{t+1}\right) \\
& =\left(1-\mathcal{K}^{0} A^{0}-\mathcal{K}^{1} A^{1}\right) \hat{x}_{t-1}^{t+1}+\mathcal{K}^{0} s_{t}+\mathcal{K}^{1} s_{t+1}
\end{aligned}
$$

where $\hat{x}_{t}^{t+1}$ is a state estimate in period $t$ using the signals up to period $t+1 . \mathcal{K}^{0}$ is the Kalman gain related to the signal in period $t$ and $\mathcal{K}^{1}$ is the Kalman gain related to the signal in period $t+1$.

Consider now that the state estimate, $\hat{x}_{t}^{t}$ follows an autoregressive process: ${ }^{20}$

$$
\hat{x}_{t}^{t}=\beta_{1} \hat{x}_{t-1}^{t}+u_{t}
$$

where $u_{t}$ is the error term. Comparing equation (B.1) with equation (B.3), we can see that $s_{t}$ and $u_{t}$ span the same linear space.

\footnotetext{
${ }^{19}$ See Fernández-Villaverde et al. (2007).

${ }^{20}$ The results in this section are presented only for auto-regressions with the state estimate. However, the forecast error, $\eta_{t}$, and consumption, $c_{t}$, are a linear function of the state estimate $\hat{x}_{t}^{i}$ and therefore the results also hold for auto-regressions with the forecast errors and consumption.
} 
Shifting by one period and rearranging equations (B.1) and (B.2) we have:

$$
\begin{aligned}
\hat{x}_{t-1}^{t}-(1-\mathcal{K} A) \hat{x}_{t-2}^{t} & =\mathcal{K} s_{t-1} \\
\hat{x}_{t-1}^{t+1}-\left(1-\mathcal{K}^{0} A^{0}-\mathcal{K}^{1} A^{1}\right) \hat{x}_{t-2}^{t+1} & =\mathcal{K}^{0} s_{t-1}+\mathcal{K}^{1} s_{t}
\end{aligned}
$$

where the first row follows from equation (B.1) and the second row from equation (B.2). From equation (B.4), we can see that $s_{t}$ can be expressed as a linear combination of $\hat{x}_{t-1}^{t}$, $\hat{x}_{t-2}^{t}, \hat{x}_{t-1}^{t+1}$ and $\hat{x}_{t-2}^{t+1}$. As $s_{t}$ and $u_{t}$ span the same linear space, $u_{t}$ can also be expressed as a linear combination of the latter four variables, which implies a regression of the form:

$$
\hat{x}_{t}^{t}=\beta_{1} \hat{x}_{t-1}^{t}+\beta_{2} \hat{x}_{t-2}^{t}+\beta_{3} \hat{x}_{t-1}^{t+1}+\beta_{4} \hat{x}_{t-2}^{t+1}+u_{t}
$$

is characterized by a perfect linear relation between the independent and dependent variables, and the corresponding VAR is therefore singular. A similar reasoning applies also to regressions involving state estimates $\hat{x}_{t}^{t+2}, \hat{x}_{t}^{t+3}, \ldots$ that are constructed by using more leads of the signal. The only difference is that the more leads of the signal are used to construct state estimates, the more lags are needed to achieve a perfect linear correlation.

The improvements in the signal - lower variance of noise shocks - can reduce the problem of singularity. Whenever improvements in the signals are perfectly correlated with the noise shocks itself - newly defined noise shocks with lower variance can be written as $v_{t}^{*}=a v_{t}$, where $v_{t}^{*}$ are noise shocks with lower variance, $a$ is a constant and $v_{t}$ are old shocks - the reduced variance of the signals does not alter the singularity problem. Namely, $s_{t}$ can still be expressed as a (different) linear combination of $\hat{x}_{t-1}^{t}, \hat{x}_{t-2}^{t}, \hat{x}_{t-1}^{t+1}$ and $\hat{x}_{t-2}^{t+1}$.

On the other hand, when correlation is not perfect - noise shocks with lower variance cannot be written as $v_{t}^{*}=a v_{t}$ - the singularity problem does not appear. To see this, we can write equation (B.4) as:

$$
\begin{aligned}
\hat{x}_{t-1}^{t}-(1-\mathcal{K} A) \hat{x}_{t-2}^{t} & =\mathcal{K} s_{t-1} \\
\hat{x}_{t-1}^{t+1}-\left(1-\mathcal{K}^{0} A^{0}-\mathcal{K}^{1} A^{1}\right) \hat{x}_{t-2}^{t+1} & =\mathcal{K}^{0} s_{t-1}^{*}+\mathcal{K}^{1} s_{t}^{*}
\end{aligned}
$$

where we use the fact that we have access to a different signal in the future, $s_{t}^{*} \neq s_{t}$ (second row). The new signal cannot be written as $s_{t}^{*}=c s_{t}$, where $c$ is a constant. Therefore, it is not possible to form a perfect linear relation between $s_{t}$ and $\hat{x}_{t-1}^{t}, \hat{x}_{t-2}^{t}$, $\hat{x}_{t-1}^{t+1}$ and $\hat{x}_{t-2}^{t+1}$. 


\section{Appendix - Real-time level GDP}

The calculation of real-time GDP is complicated by the fact that we are interested in the level of GDP, but a consistent series for GDP levels is not available from the SPF. Namely, the level forecasts from SPF are affected by changes in national accounts - for example changes in base years - and it is therefore difficult to reconstruct a consistent measure of the real-time level of GDP.

To circumvent this problem, we use a consistent revised series and use the growth rates based on the first vintages of the data to move to real-time GDP levels in period $t-1$. Specifically, the first estimate of real GDP in period $t-1$, as provided by the statistical office, $y_{t-1}^{*}$, is constructed in the following way: $y_{t-1}^{*}=y_{t-5}\left(1+\Delta^{4} y_{t-1}^{*}\right)$ where $y_{t-5}$ is the revised GDP data in period $t-5$ (based on the last available vintage in Q2 2012) and $\Delta^{4} y_{t-1}^{*}$ is the yearly growth rate of real GDP between $t-5$ and $t-1$ calculated from the first available vintage for period $t-1$, which is the one available in period $t$.

With this approximation, we do not take into account the revisions that happen after the 5-quarters, as our approximation assumes $y_{t-5}^{*}=y_{t-5}$. Although our measure can therefore underestimate the error due to the use of real time data, the revisions after five quarters are not substantial and therefore support this approximation. We could also 'went further' into the history by assuming for example, $y_{t-9}^{*}=y_{t-9}$. However, in that case we would lose additional an additional year of data, with only a limited gain (as revisions after 5 -quarters are not large). 


\section{Appendix - Estimation algorithm}

The estimation procedure consists of three steps. In the first step, we estimate the reduced-form VAR model. In the second step, we identify the structural shocks and take into account identification uncertainty. In the third step, we finally account for estimation uncertainty. In more detail, the steps are:

1. Estimate reduced-form VAR: Given the number of lags, $\widehat{p}, V A R(\widehat{p})$ is estimated assuming a non-informative Normal-Wishart prior, see Uhlig (2005) for details. A draw from posterior gives us an estimate of autoregressive coefficients and the variance-covariance of reduced form errors, $\widehat{\Sigma_{u}}$. The draw of reduced form parameters implies a reduced-form impulse response function, $\widehat{C}(L)$.

2. Identification restrictions: The non-structural impulse responses function, $C(L)$, is related to the structural impulse responses function, as $B(L)=A_{0} C(L)$, and reduced form errors, $u_{t}$, are related to structural errors, as $u_{t}=A_{0}^{-1} B \varepsilon_{t}$. Impact matrix, $S=A_{0}^{-1} B$, must satisfy:

$$
\Sigma_{u}=S S^{\prime}
$$

The QR method proposed by Rubio-Ramirez et al. (2010) is used to rotate the concatenated system to obtain the models that are consistent with the data and the sign restrictions.

- The initial estimate of $\hat{S}$ is obtained by a Cholesky decomposition of the variance-covariance matrix of reduced form errors, $\hat{\tilde{S}}=\operatorname{chol}(\hat{\Sigma})$, giving an initial estimate of the impulse response function, $\widehat{\widetilde{B}}(L)=\widehat{C}(L) \widehat{\widetilde{S}}$.

- A $n \times n$ matrix $P$ is drawn from standard normal distribution, $\mathcal{N}(0,1)$ and the QR decomposition of $P$ is derived. Note that $P=Q R$ and $Q Q^{\prime}=I$.

- The initial estimate of the impulse response function is post-multiplied by $Q$, to obtain a candidate impulse response function $\widehat{B}(L)=\widehat{C}(L) \widehat{\widetilde{S}} Q$ and $\widehat{B}(L)$ is the candidate impulse response function.

3. Distribution The steps 1-2 are repeated until the candidate impulse responses, $\widehat{B}(L)$, satisfy the identifying restrictions.

The IRF's point estimates and the related confidence bands are constructed by retaining the relevant percentiles of a distribution of 1000 retained IRFs. The same procedure is used to construct FEVD's point estimates and the related confidence bands. 


\section{E Appendix - Additional graphs}

Figure 1: Large-scale VAR - IRF to a noise shock (sign restrictions only on impact)
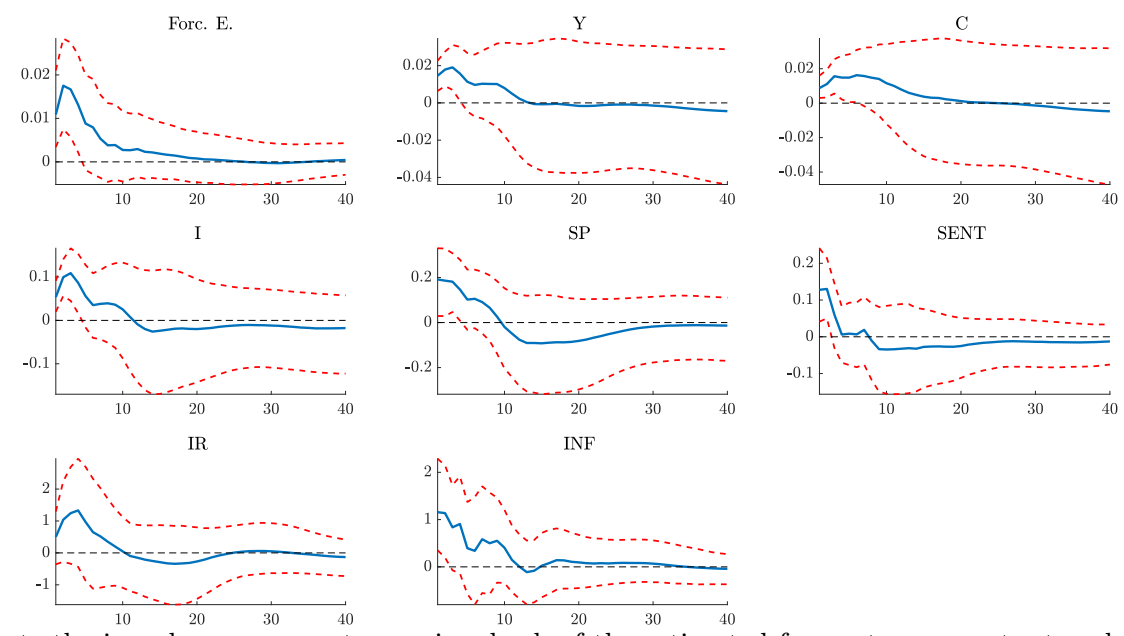

The graph presents the impulse responses to a noise shock of the estimated forecast error, output and consumption (first row), investment, stock prices and sentiment (second row) and interest rates and inflation (third row). The blue line is the point estimate and the red lines are the $68 \%$ error bands.

Figure 2: Large-scale VAR - IRF to a supply shock (sign restrictions only on impact)
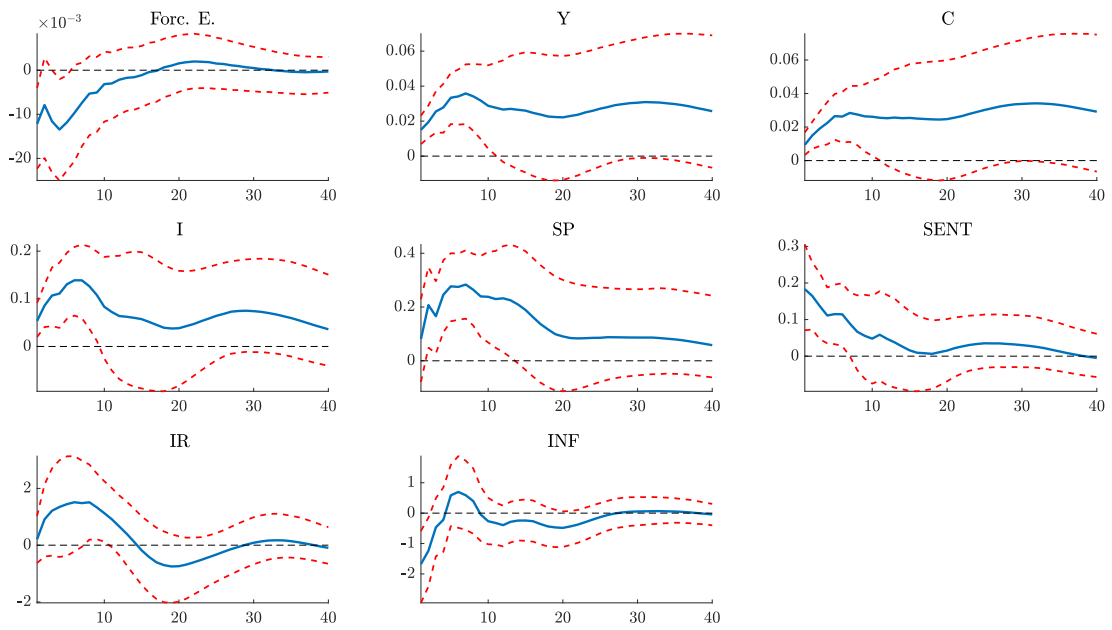

The graph presents the impulse responses to a supply shock of the estimated forecast error, output and consumption (first row), investment, stock prices and sentiment (second row) and interest rates and inflation (third row). The blue line is the point estimate and the red lines are the $68 \%$ error bands. 
Figure 3: Large-scale VAR - IRF to a noise shock (median target as in Fry and Pagan (2011))
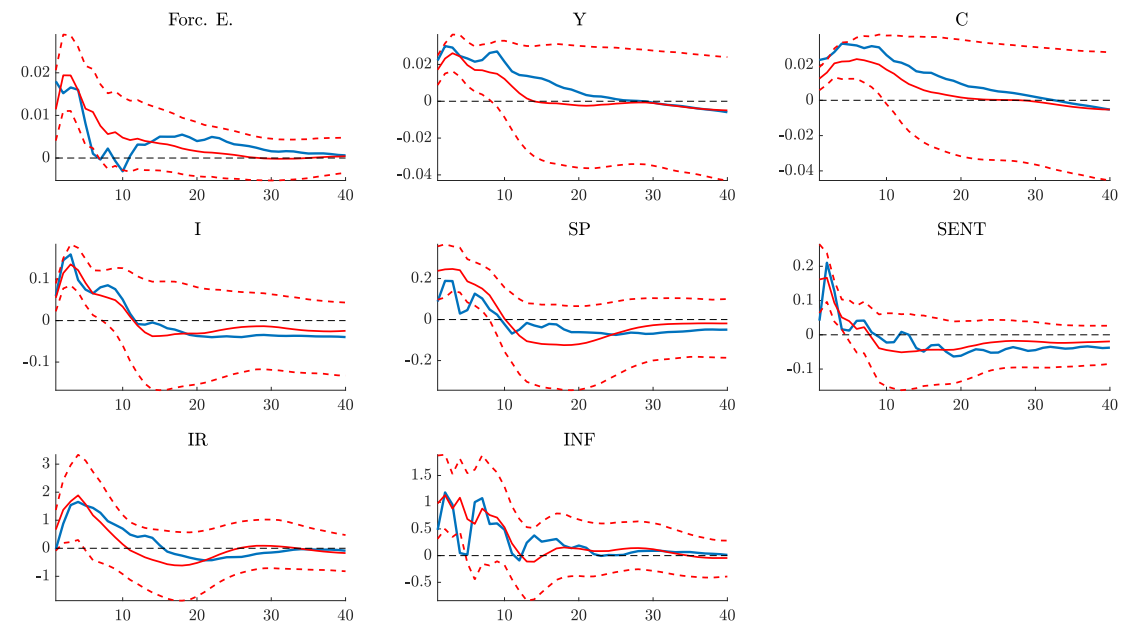

The graph presents the impulse responses to a noise shock of the estimated forecast error, output and consumption (first row), investment, stock prices and sentiment (second row) and interest rates and inflation (third row). The blue line is the median estimate using the median target method proposed in Fry and Pagan (2011). The red full line is the median estimate using our benchmark approach and the red dotted lines correspond to our baseline approach $68 \%$ error bands.

Figure 4: Large-scale VAR - IRF to a supply shock (median target as in Fry and Pagan (2011))
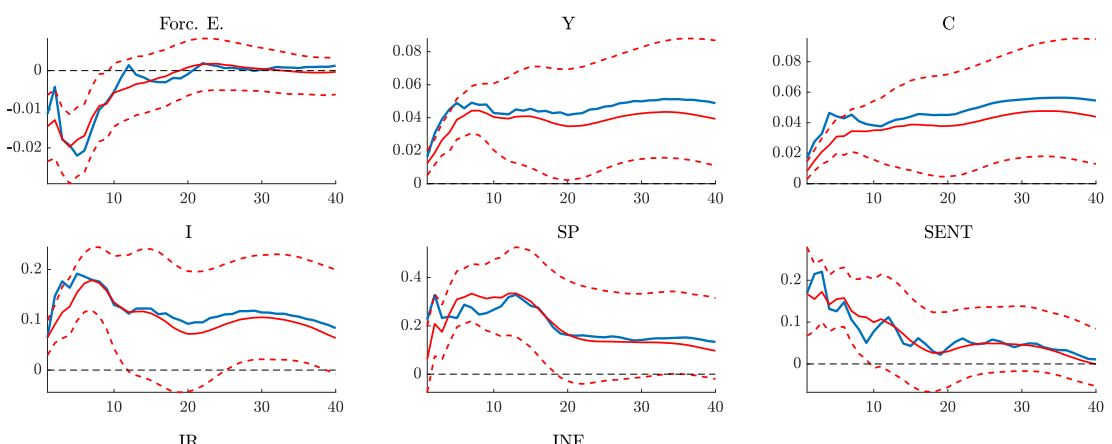

IR
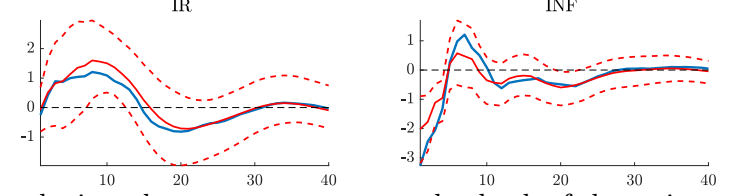

The graph presents the impulse responses to a supply shock of the estimated forecast error, output and consumption (first row), investment, stock prices and sentiment (second row) and interest rates and inflation (third row). The blue line is the median estimate using the median target method proposed in Fry and Pagan (2011). The red full line is the median estimate using our benchmark approach and the red dotted lines correspond to our baseline approach $68 \%$ error bands. 